\title{
LA MANIPULACIÓN DEL MARCO LEGAL DE LAS ELECGIONES EN AMÉRICA LATINA ENTRE 2000 Y 2012: UNA APROXIMACIÓN METODOLÓGICA
}

Irma Méndez de Hoyos

\section{INTRODUCCIÓN}

¿Hay leyes que incentivan las malas prácticas electorales? ¿Cómo identificar una ley que se ha diseñado estratégicamente para disminuir los costos de ciertas conductas electorales, como el uso de recursos públicos, la cobertura de medios sesgada o el rebase de topes de campaña? ¿Qué tanto importa el contexto para entender la manipulación estratégica de la ley?* Algunos estudios políticos comparados han documentado elecciones en ciertos países con abusos flagrantes, en que la ley otorga amplias ventajas al gobernante en turno para decidir, por ejemplo, abrir la competencia política a algún contrincante fuerte, no menos que negarle la entrada, o limitar el sufragio en ciertas regiones. ${ }^{1}$ Sin embargo, los

* Agradezco a Sarah Birch, Todd Landman, Joy Langston, Rodrigo Salazar y Tomislav Lendo por los comentarios que hicieron de este texto en sus diferentes versiones, y a Claudia Wittig, Gabriela Aguirre y Gabriel González por el apoyo en la búsqueda y sistematización de información.

${ }^{1} \mathrm{Al}$ respecto, véanse S. Birch, "Perceptions of Electoral Fairness and Voter Turnout”, Comparative Political Studies, vol. 43, núm. 12, 2010, pp. 1601-1622, y Electoral Malpractice, Oxford, University Press, 2011; M. Álvarez y F. Boehmke, "Correlates of Fraud: Studying State Election Fraud Allegations", en R. Michael Álvarez, Thad E. Hall y Susan D. Hyde (eds.), Election Fraud: Detecting and Deterring Electoral Manipulation, Washington, DC, Brookings Institution Press, 2008; J. Elklit y Andrew Reynolds, “A Framework for the Systematic Study of Election Quality”, Democratization, vol. 12, núm. 2, 2005, pp. 147-162; y P. Norris, Why Electoral Integrity Matters, Cambridge, University Press, 2014, pp. 21-39. 
casos de excesos menos evidentes, en que la ley no otorga prebendas abiertas, pero es laxa en las prohibiciones y castigos o es simplemente omisa respecto a ciertas conductas o prácticas recurrentes, han escapado por lo general al interés de los investigadores y de organismos internacionales.

En las últimas dos décadas, las elecciones en gran parte de las democracias emergentes han cambiado dramáticamente. El establecimiento de órganos de administración electoral independientes y la aprobación de nuevas leyes electorales, así como el surgimiento de múltiples opciones partidistas, han puesto las bases de elecciones democráticas en el mundo. Pese a estos cambios políticos, las malas prácticas electorales no han desaparecido y, aunque son más selectivas y menos evidentes en ciertas regiones, no por ello son menos dañinas.

Las consecuencias de las malas prácticas electorales no son pocas. Al afectar la confianza en las instituciones -Ejecutivo, Congreso, partidos y Poder Judicial-y en las elecciones, las malas prácticas electorales tienen un efecto perjudicial sobre la satisfacción con la democracia, el cumplimiento de la ley y, en última instancia, sobre la estabilidad política ${ }^{2}$ e incluso pueden repercutir en la supervivencia misma de la democracia.

Uno de los más recientes análisis comparados en el mundo muestra que, entre otras formas de manipulación, la del marco jurídico de las elecciones es la más común en América Latina. ${ }^{3} \mathrm{El}$ estudio de las leyes y los problemas de su implementación o aplicación han capturado la atención de muchas investigaciones. Sin embargo, el análisis de la manipulación del diseño de la ley, de la estructura de incentivos que genera y los costos que imprime a ciertas conductas electorales ha sido mucho más limitado. Poco se sabe, por ejemplo, sobre los tipos y áreas específicas de la manipulación del diseño de la ley, las formas o figuras legales que se usan más comúnmente y los factores que pueden estar asociados con el diseño manipulador, según lo denomina Sarah Birch. Aún más: hay poco consenso sobre cómo entender y medir la manipulación

\footnotetext{
${ }^{2}$ Véase Norris, op. cit., p. 113.
}

${ }^{3}$ Birch, op. cit., p. 48. 
del diseño de las leyes electorales en diferentes países, dado su carácter contextual, lo que explica el limitado avance de las investigaciones en este ámbito. En este sentido, la contribución primaria de este artículo es la presentación de un marco analítico y la propuesta de estrategias empíricas para identificar el diseño manipulador de las leyes electorales. Es importante aclarar que lo que estoy analizando tiene lugar en el proceso de diseño de la ley, no en la etapa de implementación o en el resultado de la elección misma.

El argumento central es que la manipulación estratégica de las leyes electorales consiste en el diseño de reglas que disminuyen o limitan los costos asociados a ciertas malas prácticas electorales mediante prohibiciones y castigos laxos o inexistentes, a partir de lo cual se crea una estructura de incentivos que abre las alternativas disponibles y, por tanto, la rentabilidad de estas prácticas, erosionando, en fin, la integridad de las elecciones democráticas. ${ }^{4}$ Con todo, el valor de los costos depende del contexto.

El propósito de esta investigación consiste entonces en presentar un marco analítico que permita tratar el problema de algunas malas prácticas electorales, así como una serie de indicadores empíricos que permitan dimensionarlas y contextualizarlas a la luz de un examen comparado. Se muestran los resultados de la aplicación de este marco en 16 países de América Latina en el periodo comprendido entre 2000 y 2012 en cuatro áreas estratégicas del proceso electoral: 1) cobertura de los medios de comunicación; 2) topes de gastos de campaña; 3) órganos de administración electoral; y 4) uso de los recursos del Estado.

${ }^{4}$ IDEA ("Deepening Democracy: A Strategy for Improving the Integrity of Elections Worldwide", The Report of the Global Commission on Elections, Democracy and Security, 2012) define las elecciones con integridad como cualquier elección basada en los principios democráticos de sufragio universal y equidad política, reflejados en estándares y acuerdos internacionales, que es profesional, imparcial y transparente en su preparación y administración a lo largo de todo el ciclo electoral. Además, Pippa Norris (op. cit.) señala que el concepto de "integridad electoral" se refiere tanto a los convenios internacionales como a las normas globales aplicadas de forma universal a todos los países durante el ciclo electoral. 
Los hallazgos que se presentan se basan en el análisis de fuentes primarias de información que incluyen datos de encuestas de opinión pública y las leyes electorales por país que se enlistan a continuación: de Argentina, el Código Electoral Nacional, Decreto No. 2135 de 1983 (con modificaciones posteriores), la Ley de Financiamiento de los Partidos Políticos, Ley 26.215, y la Ley de Democratización de la Representación Política, la Transparencia y la Equidad Electoral; de Bolivia, la Ley del Régimen Electoral, Ley No. 026, y la Ley del Órgano Electoral Plurinacional, Ley No. 018, ambas de 2010; de Chile, la Ley 19884 sobre Transparencia, Límite y Control del Gasto Electoral de 2013, la Ley No. 18.700 Ley Orgánica Constitucional sobre Votaciones Populares y Escrutinios de 2012, la Ley No. 18.556 Ley Orgánica Constitucional sobre Sistema de Inscripciones Electorales y Servicio Electoral de 2012 y la Ley Orgánica Constitucional del Tribunal Calificador de Elecciones de 2012; de Colombia, la Constitución Política de 2005, el Decreto 2241 de 1986 Código Electoral de 1986, Código Penal de 2000 y la Ley 130, del 23 de Marzo de 1994 Estatuto Básico de los Partidos y Movimientos Políticos de 1994; de Costa Rica, el Código Electoral Ley No. 8765 de 2009, la Constitución Política de 1949 (con reformas posteriores) y la Ley Orgánica del Tribunal Supremo de Elecciones y del Registro Civil Ley No. 3504 de 1965; de Ecuador, la Ley Orgánica Electoral Código de la Democracia de 2009; de El Salvador, el Código Electoral de 2012 y el Código Penal; de Guatemala, la Ley Electoral y de Partidos Políticos Decreto No. 1-85 de 2007; de Honduras, la Ley Electoral y de las Organizaciones Políticas y sus reformas de 2004, la Constitución Política de 1982 y el Decreto No. 307; de México, el Código Federal de Instituciones y Procedimientos Electorales de 1996 (vigente en las elecciones de 2006) y el Código Federal de Instituciones y Procedimientos Electorales de 2008; de Nicaragua, la Ley Electoral Ley No. 331 de 2000; de Panamá, el Código Electoral de 2007 y la Constitución Política de 2004; de Paraguay, la Ley No. 834 Código Electoral de 1996 y la Constitución Política de 1992; de Perú, la Ley Orgánica de Elecciones No. 26859, la Ley de Partidos Políticos de 2003, el Código Penal y la Constitución Política de 2005; de Uruguay, la Ley de Elecciones de 2000 y la Constitu- 
ción Política de 1967; y de Venezuela, la Ley Orgánica de Procesos Electorales, la Ley Orgánica del Poder Electoral de 2002 y la Constitución Política de 2009.

El presente texto se divide en tres secciones. En la primera se presenta la discusión conceptual y metodológica sobre las malas prácticas electorales, así como el marco analítico para examinar la manipulación del diseño de las leyes electorales; en la segunda, los elementos del entorno latinoamericano que permiten entender el carácter contextual de las leyes electorales; en la tercera, la aplicación del marco analítico en los países de América Latina que aquí se estudia, así como un caso que ejemplifica la manipulación del diseño de las leyes electorales en el periodo comprendido entre 2000 y 2012 y la relevancia del contexto.

EL MARCO ANALÍTICO PARA ESTUDIAR LA MANIPULACIÓN ESTRATÉGICA DEL DISEÑO DE LAS LEYES ELECTORALES

\section{Definiciones y aproximaciones metodológicas}

Los trabajos comparados muestran una gran diversidad en la forma de entender y medir las prácticas que erosionan la calidad o integridad de las elecciones. En el cuadro 1 se presentan algunas de las definiciones más importantes de estos fenómenos, su forma de medirlas y el tipo de fuente de información utilizada. Según se observa, no hay un consenso sobre cómo entender la manipulación electoral. Como bien señala Simpser, los académicos y los profesionales usan gran variedad de términos para calificar normativamente una elección de fraudulenta y expresiones como "corrupción electoral", "manipulación electoral", "mala conducta electoral", "patronazgo" y "clientelismo". ${ }^{5}$ Lo cierto es que el entendimiento teórico y empírico de estos fenómenos es aún limitado y hay un amplio espacio para el desacuerdo con respecto de su significado, sus causas y consecuencias.

${ }^{5}$ Why Governments and Parties Manipulate Elections. Theory, Practice, and Implications, Cambridge, University Press, 2013, p. 32. 


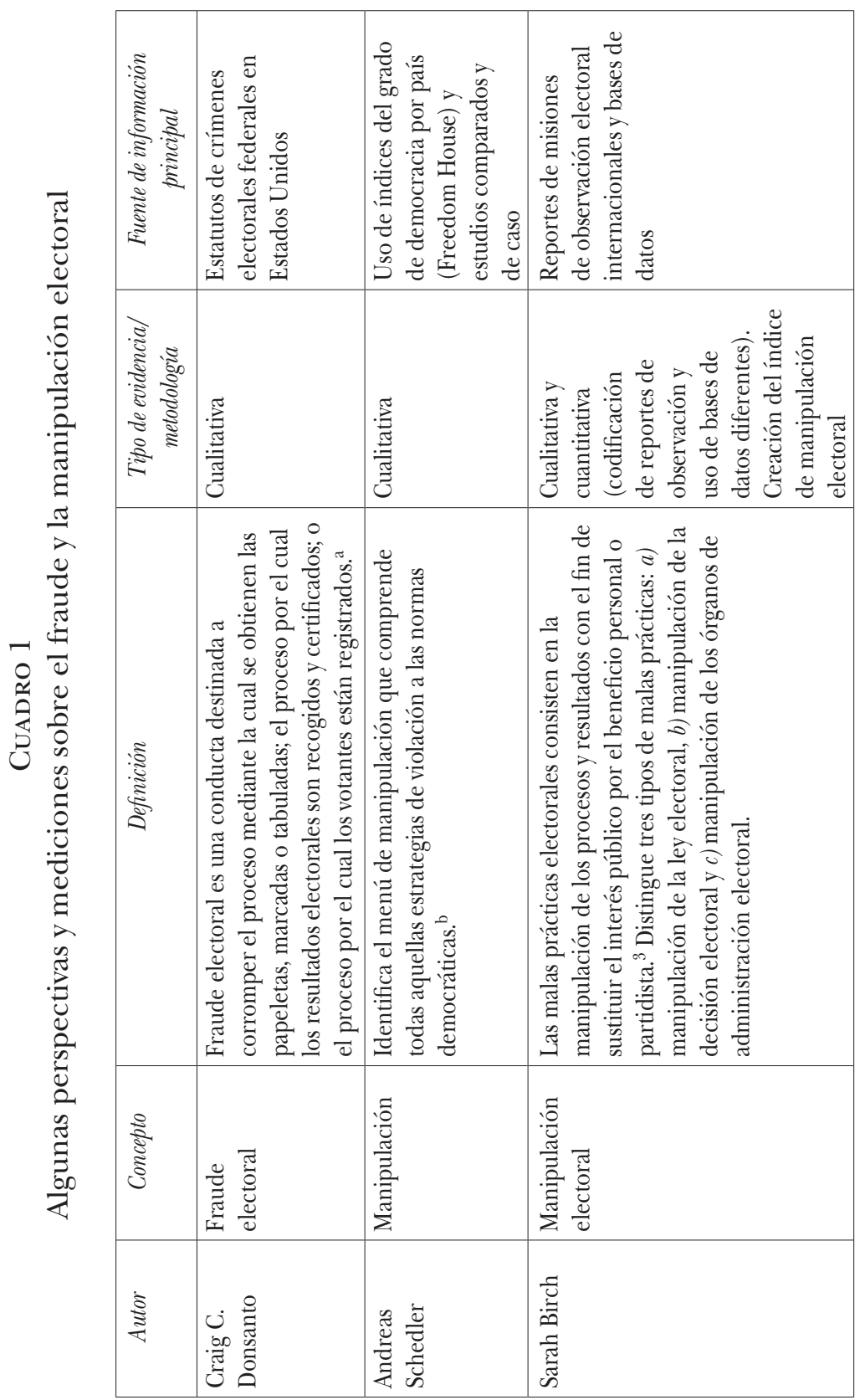




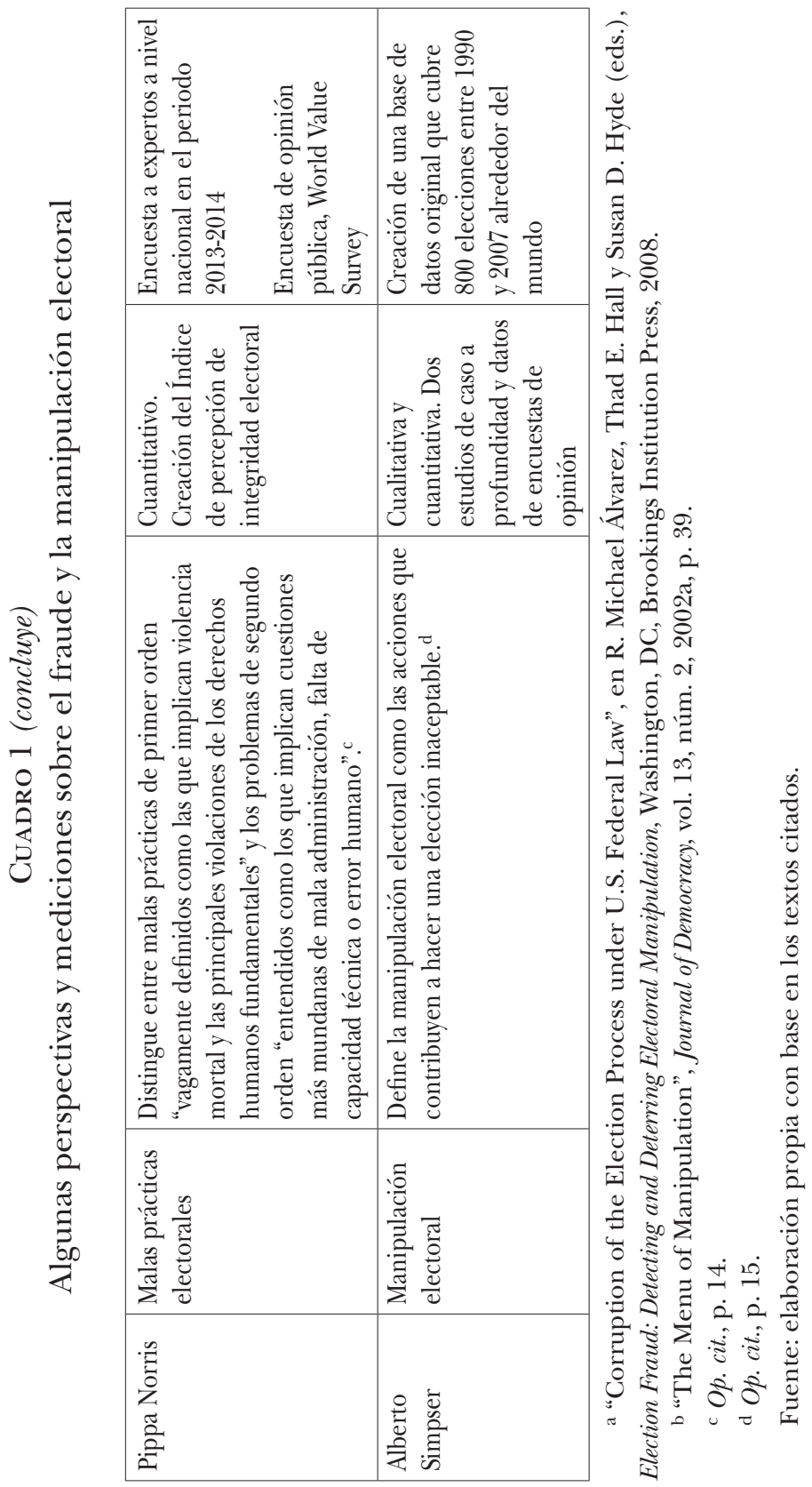


A esto se suma una importante heterogeneidad metodológica, esto es en la forma de tratarlos, el tipo de evidencia sobre la que sustentan sus hallazgos y las fuentes de información utilizadas. El uso de estudios de caso es, sin duda, muy importante. Éstos permiten contextualizar el tamaño de la manipulación electoral y, a la vez, ganar profundidad en el análisis, pero su capacidad de generalización es muy limitado. Por su parte, los estudios comparados muestran que los mecanismos de manipulación electoral utilizados en diversos países tienen cada vez más rasgos semejantes, en una o varias dimensiones. Pese a los avances que representan estos estudios y otros más, persiste la discusión sobre los tipos de regímenes políticos en los que se dan estos fenómenos y su influencia, así como sobre su tipología específica, es decir por tipo de manipulación o mala práctica.

A propósito, Álvarez, Hall y Hyde reconocen que "el concepto de fraude electoral y manipulación electoral de manera más general sigue siendo muy poco estudiado". ${ }^{6}$ Estos autores sugieren que uno de los factores que hacen que sea difícil formular una comprensión coherente del fraude se relaciona con el contexto, pues su comprensión cabal depende de ello. ${ }^{7} \mathrm{Al}$ mismo tiempo, hay serios problemas de recolección de datos y pruebas, según el encubrimiento intencional de las malas prácticas y el fraude, y claramente se vislumbra un desarrollo teórico limitado en este campo.

El análisis del marco legal de las elecciones bajo la perspectiva de integridad y malas prácticas es un territorio casi inexplorado. ${ }^{8}$ Claro está que hay una larga tradición de estudios que analizan las instituciones electorales de diferentes maneras. Uno de los enfoques más importantes estudia las consecuencias políticas de los sistemas electorales, como los de representación proporcional y de sistemas de mayoría. ${ }^{9}$ También hay otro conjunto de estudios que cit., p. 1.

6 "Introduction: Studying Election Fraud", en Álvarez, Hall y Hyde (eds.), op.

${ }^{7}$ Loc. cit.

${ }^{8}$ Véase L. Massicotte, A. Blais y A. Yoshinaka (eds.), Establishing the Rules of the Game. Election Laws in Democracies, Toronto, University Press, 2004.

${ }^{9}$ Cf. A. Lijphart, Electoral Systems and Party Systems. A Study of Twenty-Seven Democracies, 1945-1990, Oxford, University Press, 1994, y R. Taagepera y M. S. Shugart, Seats and Votes: The Effects and Determinants of Electoral Systems, Nueva York, Yale University Press, 1989. 
analiza el gerrymandering y otras formas similares de manipulación de la representación. Todos éstos se han concentrado en el efecto o incidencia de ciertas reglas, tras la estela de las ideas centrales del institucionalismo clásico, y han puesto menos atención en la forma en que las reglas fueron diseñadas.

A la luz del institucionalismo, las instituciones se conciben para establecer el orden y reducir la incertidumbre en los intercambios. Proveen la estructura de incentivos de una sociedad, ${ }^{10}$ permiten y limitan a los actores políticos, y proveen códigos de apropiación de conducta, lazos afectivos y la creencia en un orden legítimo. ${ }^{11}$ Uno de los límites del paradigma institucional es que, toda vez que las instituciones son diseñadas a menudo por las mismas élites que deben someterse a su mandato, es difícil saber si las instituciones explican el comportamiento político, o simplemente reflejan y codifican las preferencias de las élites por un cierto modelo de interacción. ${ }^{12}$ A este debate, según el cual las normas explican los comportamientos de los actores o reflejan sus preferencias, se suman los problemas de enforcement o aplicación de la ley y, más recientemente, lo que Holland llama la "no aplicación selectiva de la ley", esto es cuando la ley se aplica según los cálculos electorales de los partidos. Para Simpser, cuando una norma se aplica, según los intereses del gobernante en turno sobre ciertos partidos y no otros, las reglas electorales se convierten en "un instrumento de control político". ${ }^{13}$

Ahora bien, desde la perspectiva institucionalista se puede interpretar que todas las leyes electorales se manipulan, de alguna forma, según integran normas que imponen costos y beneficios a los diferentes actores. ${ }^{14}$ Los umbrales para obtener asientos de representación en el Congreso son un clásico ejemplo de la forma en

${ }^{10}$ D. C. North, "Institutions", The Journal of Economic Perspectives, vol. 5, núm. 1, 1991, pp. 97-112.

${ }^{11}$ March y Olsen, "Elaborating the «New Institutionalism»", en Sarah A. Binder, R. A. W. Rhodes y Bert A. Rockman (eds.), Oxford Handbook of Political Institutions, Oxford, University Press, 2006, p. 4.

12 A. Przeworski, "Institutions Matter?", Government and Opposition, vol. 39, núm. 2, 2004, pp. 527-540.

13 Op. cit., p. 51.

${ }^{14}$ Véanse Norris, op. cit., y North, art. cit., p. 98. 
que las reglas benefician a algunos partidos e imponen costos a otros. Concuerdo con Sarah Birch cuando concibe la manipulación de la ley electoral como un proceso mediante el cual las reglas se diseñan con el fin de facilitar el fraude o la corrupción, o para bajar los costos asociados con otras formas de malas prácticas. ${ }^{15}$

Así pues, las reglas electorales estructuran incentivos que imponen costos a diversos actores, pero cuya valoración parece depender del contexto. El enfoque denominado institucionalismo contextualizado que propone Dieter Nohlen parte de la premisa según la cual en la estabilidad, eficacia y rendimiento de las instituciones políticas, muchas veces el contexto "hace la diferencia". ${ }^{16}$ En su exposición sobre las reformas electorales en América Latina, Nohlen invita a no olvidar que "las instituciones, en sus efectos, son dependientes del contexto, es decir de la configuración de otras variables con las cuales constituyen el conjunto en el que operan las variables observadas". ${ }^{17}$ Los supuestos del institucionalismo contextualizado confirman que el valor relativo de los costos depende precisamente del contexto. ${ }^{18}$

Con base en ello, en el marco de esta investigación la manipulación estratégica del diseño del marco jurídico que rige las elecciones se define como el proceso por el cual los actores políticos en el sistema disminuyen o limitan los costos asociados con ciertas malas prácticas electorales mediante prohibiciones y castigos laxos o inexistentes, a partir de lo cual se crea una estructura de incentivos que abre las alternativas disponibles y, por tanto, la rentabilidad de esas prácticas, que dañan o erosionan la integridad de las elecciones democráticas. Sin embargo, el valor relativo de los costos

15 Op. cit., p. 75.

${ }^{16}$ Véase R. Ortiz, “Contextos, instituciones y actores políticos: Dieter Nohlen y el estudio de las instituciones en América Latina”, en Dieter Nohlen, El institucionalismo contextualizado. La relevancia del contexto en el análisis y diseño institucionales, Porrúa-Universidad Nacional Autónoma de México, 2006, pp. 1-30.

17 Ibidem, p. 54.

${ }^{18}$ Los principales supuestos del institucionalismo contextualizado son: $a$ ) valor relativo de las instituciones dependiente de las variables de contexto; $b$ ) concepción causal compleja que trata de registrar la interacción mutua entre diversos factores en situaciones concretas; por tanto, $c$ ) elaboración de generalizaciones de medio alcance y $d$ ) recomendaciones adaptadas al caso concreto. 
asociados a las reglas electorales manipuladas depende del contexto y los casos concretos. En general, es de suponer que en la medida en que una ley electoral prohíbe y castiga ciertas malas prácticas electorales, se elevan los costos políticos y de legitimidad de llevarlas a cabo, a la vez que la ausencia de prohibiciones y castigos los disminuye. No obstante, el análisis del costo-beneficio que hacen los actores de las reglas del juego depende de valores exógenos.

Es de mencionar que en el marco de esta investigación utilizo como sinónimos la manipulación electoral y las malas prácticas electorales siguiendo a Sarah $\operatorname{Birch}^{19}$ y tomando en cuenta que prevalece la falta de consenso en la bibliografía especializada. También cabe señalar que la manipulación estratégica del marco jurídico que estoy analizando tiene lugar en el proceso de diseño de ley, antes que en la etapa de implementación o el resultado de la elección misma. Me concentro entonces en aquellas situaciones en las que "los actores políticos promovieron la opción de participar en la manipulación electoral, independientemente de quién termina ganando", ${ }^{20}$ y, por tanto, no se evalúa la manipulación de la ley por los resultados electorales, ni se intenta explicar la manipulación de la ley o su relación causal con otros factores. Éstos son objetivos relevantes, pero ajenos a esta investigación.

\section{El marco de análisis y los indicadores}

Por estudios anteriores, ${ }^{21}$ se sabe que hay formas comunes de malas prácticas electorales en América Latina, que tienen lugar en diferentes etapas del ciclo electoral. Sin embargo, hay algunas que

19 Op. cit., p. 75.

20 Simpser, op. cit., p. 8.

21 Como los de Álvarez y Boehmke, art. cit.; Álvarez y T. E. Hall. Electronic Elections: The Perils and Promises of Digital Democracy, Nueva Jersey, NJ, Princeton University Press, 2010; Sarah Birch, art. cit. y op. cit.; Elklit y Reynolds, art. cit.; J. Hartlyn, J. McCoy y T. M. Mustillo, "La importancia de la gobernanza electoral y la calidad de las elecciones en la América Latina contemporánea”, América Latina Hoy, vol. 51, núm. 1, 2009, pp. 15-40; y F. Lehoucq, "Bolivia's Constitutional Breakdown”, Journal of Democracy, vol. 19, núm. 4, 2008, pp. 110-124. 
afectan de manera directa la integridad de las elecciones, al alterar las condiciones de la competencia. Susan Levitsky y Lucan Way reconocen tres formas principales para desnivelar el campo político de competencia: la disparidad en los recursos, el acceso diferenciado a los medios y el acceso desigual a la ley. ${ }^{22}$ Zovatto y Griner, e IDEA Internacional, señalan los gastos de campaña como uno de los factores que mayores ventajas pueden dar a ciertos contendientes. ${ }^{23}$ Respecto a los órganos electorales, Hartlyn, McCoy y Mustillo, así como S. Birch, reivindican la importancia de su conformación y destacan su independencia de iurey de facto, además de influencia en la calidad de las elecciones. ${ }^{24}$

En conjunto, parece haber un amplio consenso sobre la importancia de ciertas áreas en que recurrentemente se han registrado malas prácticas electorales, a saber: medios de comunicación, gastos de campaña, recursos públicos y órganos electorales. Esta investigación se concentra en estas cuatro áreas de gran preocupación en América Latina, aunque reconoce que hay otras prácticas como la compra de votos, que se ha ido extendiendo en muchos países de la región y del mundo y sobre la cual no suele haber evidencia empírica sistematizada.

Ahora bien, ¿cómo podemos identificar una ley manipulada en estas áreas? Sarah Birch, tras la estela de Goodwin-Gill, ${ }^{25}$ reconoce que es difícil determinar si alguna regulación particular constituye una violación a las normas democráticas ${ }^{26}$ y sugiere juzgar las leyes

22 "Why Democracy Needs a Level Playing Field in Journal of Democracy", Journal of Democracy, vol. 21, núm. 1, 2010, p. 58. Retomo el concepto de "campo de juego desnivelado" (o unlevel playing field) de Levitsky y Way, quienes lo definen como un campo en el que el abuso del titular del Estado genera tales disparidades en el acceso a los recursos, medios de comunicación o instituciones estatales, que la capacidad de los partidos de oposición para organizar y competir por los cargos nacionales se ve seriamente deteriorada.

${ }^{23}$ De las normas a las buenas prácticas. El desafio del financiamiento político en América Latina / From Norms to Good Practices. The Challenge of Political Finance in Latin America, San José, Costa Rica, Organization of the American States and IDEA International, 2004.

${ }^{24}$ Véanse sus respectivas obras citadas.

25 Op. cit., p. 30.

${ }^{26}$ Loc. cit. 
electorales según los efectos prácticos que tienen en el proceso electoral en un estado o contexto determinado. La perspectiva de integridad y malas prácticas sugiere recurrir a los acuerdos internacionales y códigos de mejores prácticas electorales mundiales relativas al contenido de las leyes. De esta forma es posible conocer las recomendaciones o estándares esperados en el proceso electoral y contrastarlas con el contenido de las leyes electorales latinoamericanas que se estudian. El cuadro 2 sintetiza algunas de las recomendaciones más relevantes con respecto de las cuatro áreas estudiadas en esta investigación:

\section{CuAdro 2}

Normas globales y códigos de buenas prácticas electorales alrededor del mundo en áreas críticas del proceso electoral

\begin{tabular}{ll}
\hline Área & Acuerdos internacionales, normas globales y mejores prácticas electorales \\
\hline $\begin{array}{l}\text { 1. Uso de } \\
\text { recursos }\end{array}$ & Código de buenas prácticas en materia electoral. Comisión europea para la \\
estatales & democracia por el derecho. \\
& Igualdad de Oportunidades: ${ }^{\text {a }}$ \\
& Deberá garantizarse la igualdad de oportunidades entre los partidos y los \\
& candidatos. Ello implica la neutralidad de las autoridades públicas, en \\
& particular por lo que se refiere a: \\
& i) Campaña electoral \\
& ii) Cobertura por los medios, en particular los medios públicos \\
iii) La financiación pública de los partidos y de las campañas.
\end{tabular}

\footnotetext{
2. Sesgo Medios de las campañas electorales (2007).

en la Recomendaciones sobre medidas relativas a la cobertura por los medios cobertura de las campañas electorales ${ }^{\mathrm{b}}$ (2007).

mediática Principios:

Publicidad política pagada

Los marcos regulatorios deberán asegurar que todos los partidos que se enfrentan tengan la posibilidad de comprar espacios publicitarios en las mismas condiciones y con las mismas tarifas de pago.

Los presentadores habituales de noticias y los programas de actualidad no deberán tomar parte en publicidad política pagada.

Los países miembros deberán adoptar medidas con las cuales los medios que pertenecen a las entidades públicas, cuando cubran campañas electorales, lo hagan de manera justa, equilibrada e imparcial, sin discriminar ni apoyar a un partido político o candidato específico. Si dichos canales aceptan publicidad política pagada en sus publicaciones, deberán asegurarse de que todos los aspirantes
} 


\begin{tabular}{ll}
\hline Área & \multicolumn{1}{c}{ Acuerdos internacionales, normas globales y mejores prácticas electorales } \\
\hline & políticos y partidos que solicitan la compra de espacio publicitario sean \\
tratados de forma equitativa y no discriminatoria.
\end{tabular}

a Comisión Europea para la Democracia por el Derecho, Código de buenas prácticas en materia electoral. Directrices e informe explicativo, introd. de María del Carmen Alanis Figueroa, pról. de Gianni Buquicchio, México, Tribunal Electoral del Poder Judicial de la Federación, 2011.

b Loc. cit. Recomendación de 2007; Declaración de principios para la observación internacional de elecciones, acto de conmemoración celebrado en las Naciones Unidas, Nueva York, 27 de octubre de 2005.

${ }^{\mathrm{c}}$ Loc. cit. Recomendación de 2003.

${ }^{\mathrm{d}}$ Loc. cit.

Fuente: elaboración propia con base en los textos citados. 
Según se observa en el cuadro 2, las normas globales y los códigos de buenas prácticas en materia electoral de la Comisión europea para la democracia incluyen una serie de recomendaciones que apuntan muy claramente a la incorporación de normas electorales que establezcan prohibiciones y sanciones en ciertas áreas. Destacan por su claridad las recomendaciones en materia de gastos de campaña, entre las que se sugiere establecer límites a tales gastos, así como un monitoreo independiente sobre el financiamiento y los gastos realizados. Incluso se exhorta a exigir que la violación de las reglas en esta área esté sujeta a sanciones eficaces, proporcionales y disuasivas.

Otra de las áreas donde hay recomendaciones de importancia es la de los órganos electorales. Los códigos de buenas prácticas señalan que la aplicación de las normas electorales, y en particular el conteo de votos, deberá estar en manos de un órgano electoral imparcial y que es recomendable crear comisiones electorales independientes e imparciales a todos los niveles, desde el nacional hasta la mesa electoral.

Las leyes electorales en el mundo suelen contener normas cada vez más explícitas en estas y otras áreas y establecer lo que prohíben y castigan o no, que se traduce en costos -altos, medios o bajos-, cuyo valor relativo para los actores depende del contexto. En este sentido, las leyes electorales elevan los costos de las malas prácticas electorales al prohibir y castigar o, por el contrario, los disminuyen al no prohibir y no castigar. En el marco analítico que aquí se propone, el contenido de la ley, lo que explícitamente se prohíbe y se castiga o, por el contrario, lo que no se prohíbe y no se castiga, constituye el indicador de los costos que imprime la norma a los actores, lo que denominó en su conjunto la manipulación del diseño de las leyes electorales.

El análisis de esta manipulación se desarrolla a partir de la codificación de las leyes electorales. Se detecta en cada una de ellas lo que prohíben en relación con las malas prácticas electorales en las áreas de interés y los castigos asociados a estas prácticas. En todos los casos, se espera que las leyes electorales recojan las recomendaciones contenidas en los códigos de buenas prácticas en materia electoral, esto es que establezcan topes de campa- 
ña y prohíban el partidismo de los órganos electorales, el uso de recursos públicos y la cobertura mediática sesgada. El cuadro siguiente describe los indicadores de la manipulación del diseño del marco legal de las elecciones en las cuatro áreas electorales tratadas:

\section{Cuadro 3}

Marco analítico de la manipulación del diseño de las leyes electorales

\begin{tabular}{cc}
\hline & $\begin{array}{c}\text { Marco legal } \\
\text { (reglas electorales) }\end{array}$ \\
\hline $\begin{array}{c}\text { Recursos del } \\
\text { Estado }\end{array}$ & $\begin{array}{c}\text { Grado en el que la ley electoral: } \\
\text { a) prohíbe el uso de recursos del Estado; } \\
\text { b) castiga el uso de recursos del Estado. }\end{array}$ \\
\hline Cobertura & $\begin{array}{c}\text { Grado en el que la ley electoral: } \\
\text { mediática }\end{array}$ \\
& a) prohíbe la cobertura mediática sesgada; \\
butoridad & Grado en el que la ley electoral: \\
electoral & a) prohíbe el sesgo partidista del órgano electoral; \\
& b) castiga el sesgo partidista del órgano electoral. \\
\hline Gastos de & Grado en el que la ley electoral: \\
campaña & a) prohíbe el gasto excesivo durante campañas con \\
& gastos de campaña; \\
& b) castiga el rebase de topes de campaña.
\end{tabular}

Fuente: elaboración de la autora.

En esta perspectiva, que combina la prohibición y el castigo de las malas prácticas electorales en la ley, se advierten cuatro escenarios, que se presentan en el cuadro 4 . El primero incluye los casos en los que las leyes electorales prohíben y castigan las malas prácticas electorales. En este escenario, la ley pretende servir como disuasivo de las malas prácticas elevando los costos de transacción, al prohibirlas y castigarlas. Un segundo escenario está integrado por casos en los que la ley sí prohíbe las malas prácticas, pero no incluye un castigo aso- 
ciado con las mismas, con lo que modera o limita los costos asociados con sus propias normas. Un tercer escenario, poco común, es aquel en que la ley no incluye una prohibición específica, pero sí contempla algún castigo genérico para las malas prácticas. Aquí, la estructura de incentivos es contradictoria y hasta confusa, y puede servir para abrir espacios de discrecionalidad en la aplicación de la ley. El cuarto escenario se constituye de lo casos en los que las leyes electorales no prohíben y no castigan las prácticas indeseables en las áreas estudiadas. En estos casos, las leyes representan una violación a las normas globales de integridad electoral, al tiempo que disminuyen los costos de legitimidad que deberían pagar los actores políticos que incurren en malas prácticas.

Cuadro 4

Relación entre prohibiciones y castigos en la legislación

\begin{tabular}{|c|c|c|}
\hline & $\begin{array}{c}\text { Sí hay castigos señalados en la } \\
\text { legislación electoral }\end{array}$ & $\begin{array}{c}\text { No hay castigos señalados en la } \\
\text { legislación electoral }\end{array}$ \\
\hline $\begin{array}{l}\text { Sí hay } \\
\text { prohibición } \\
\text { explícita en } \\
\text { la legislación } \\
\text { electoral }\end{array}$ & $\begin{array}{l}\text { Casos cuya legislación electoral vi- } \\
\text { gente al momento de la elección } \\
\text { señalan explícitamente la prohibi- } \\
\text { ción y castigo de malas prácticas } \\
\text { electorales en todas o la mayoría } \\
\text { de las cuatro áreas estudiadas.* }\end{array}$ & $\begin{array}{l}\text { Casos cuya legislación electoral vi- } \\
\text { gente al momento de la elección se- } \\
\text { ñalan explícitamente la prohibición } \\
\text { de malas prácticas electorales en to- } \\
\text { das o la mayoría de las cuatro áreas } \\
\text { estudiadas, pero no se incluyen los } \\
\text { castigos para inhibir estas prácticas. }\end{array}$ \\
\hline $\begin{array}{l}\text { No hay } \\
\text { prohibición } \\
\text { en la } \\
\text { legislación } \\
\text { electoral }\end{array}$ & $\begin{array}{l}\text { Casos cuya legislación electoral vi- } \\
\text { gente al momento de la elección } \\
\text { no menciona explícitamente la } \\
\text { prohibición de las malas prácticas } \\
\text { electorales en todas o la mayoría } \\
\text { de las cuatro áreas estudiadas, pero } \\
\text { incluye castigos generales aplica- } \\
\text { bles a discreción. }\end{array}$ & $\begin{array}{l}\text { Casos cuya legislación electoral vi- } \\
\text { gente al momento de la elección no } \\
\text { prohíbe y no castiga las malas prácti- } \\
\text { cas electorales en todas o la mayoría } \\
\text { de las cuatro áreas estudiadas. }\end{array}$ \\
\hline
\end{tabular}

*Hay leyes con algún grado de prohibición, pero cuya ambigüedad permite varias interpretaciones y abre espacios de discrecionalidad amplios.

Fuente: la autora, con información obtenida de la revisión de la legislación electoral de los países mencionados. 
En cualquiera de los escenarios, el valor de los costos que imprimen las normas electorales son contextuales, de modo tal que si el contexto está marcado por la desconfianza en las instituciones y un frágil estado de derecho -por tanto, mayor impunidad y corrupción- es de esperar que las prohibiciones y castigos no logren elevar los costos de llevar a cabo las malas prácticas electorales, es decir que no logren disuadir a los actores, pues en los hechos los costos son bajos o casi nulos o pueden evitarse. Por el contrario, en países donde el estado de derecho es más sólido y la confianza en las instituciones es mayor, las prohibiciones y castigos de las leyes electorales elevan los costos de cometer conductas ilícitas, de las cuales, por tanto, los actores políticos podrían quedar persuadidos de no cometerlas.

\section{El CONTEXTO LATINOAMERICANO}

Los procesos de transición a la democracia en América Latina forman parte, según Huntington, de la tercera ola de democratización en el mundo moderno que comenzó en Lisboa, Portugal, en 1974, cuando cesó la dictadura que había nacido tras un golpe militar semejante en 1926. Huntington apunta que durante los quince años siguientes al final de la dictadura portuguesa, aproximadamente en treinta países de Europa, Asia y América Latina, los regímenes autoritarios fueron reemplazados por otros democráticos. En otros países, se produjo una considerable liberalización y los movimientos a favor de la democracia cobraron fuerza, a más de legitimarse. A finales de los años setenta, la ola democrática avanzó hacia Latinoamérica, donde países como Ecuador, Bolivia, Uruguay y Argentina vivieron la caída de gobiernos militares y la elección de presidentes civiles. Más tarde, Brasil alcanzó un punto decisivo con la elección del primer presidente civil desde 1964, mientras El Salvador y Guatemala hicieron lo mismo en 1984 y 1985 respectivamente. ${ }^{27}$

27 Véase S. P. Huntington, La tercera ola. La democratización a finales del siglo XX, trad. de Josefina Delgado, Barcelona, Paidós, 1994. 
Este proceso de cambio despertó muchas expectativas respecto a la capacidad de las democracias emergentes para generar desarrollo económico y un entusiasmo, en alguna medida desbordado, con respecto de los cambios económicos, sociales y políticos futuros. Pese a ello, ya en la década de los noventa, las democracias latinoamericanas empezaban a mostrar escasos avances en materia económica, principalmente de combate a la pobreza y desigualdad y un lento o nulo incremento del ingreso y bienestar general de la población. La distancia entre las expectativas económicas derivadas del cambio político y la realidad contribuyó a generar una marcada y creciente decepción entre estudiosos. Éstos cuestionaron la capacidad de las democracias latinoamericanas no sólo para consolidar los cambios políticos alcanzados, sino, sobre todo, para avanzar hacia lo que se había dado por sentado, es decir que la democracia traería automáticamente desarrollo económico, justicia social y consolidación de las instituciones políticas democráticas, entre ellas las elecciones.

Numerosos estudios políticos comparados han demostrado que, en las últimas dos décadas, las elecciones en América Latina se han transformado hasta tenerse por limpias, libres y competitivas. ${ }^{28}$ Los ciudadanos gozan de derechos y libertades que han sido incorporados a las respectivas constituciones y a las leyes en materia

${ }^{28}$ Hay seis índices que ofrecen una evaluación general de la calidad de la democracia en América Latina, los cuales incluyen al menos una dimensión crítica para el estudio de las elecciones en la región. Entre los más relevantes se encuentran el Índice de Democracia de la Unidad de Inteligencia Económica; el Índice de Consolidación de la Democracia; la Clasificación de los Regímenes en América Latina; el Índice de Polity y el Índice de Global Integrity. El Índice de Democracia Electoral (IDE) es el único que se concentra en las elecciones. Fue creado por Gerardo Munck en colaboración con Jay Verkuilen para el Programa de las Naciones Unidas para el Desarrollo (PNUD) y presentado en el informe de la Democracia en América Latina, PNUd, 2004. Una de las características más notables es que, a pesar de las diferencias en los enfoques, indicadores, fuentes de información y datos, los resultados de los índices confirman claramente que las elecciones son, en su mayoría, libres y competitivas. Muchas de ellas también son limpias y garantizan competencia y participación abiertas en la mayoría de los países de América Latina, aunque estas características aún varían de uno a otro. 
electoral. Además, autoridades profesionales e independientes organizan las elecciones y organismos nacionales e internacionales monitorean indistintamente el ciclo electoral. A pesar de este progreso democrático indiscutible, viejas y nuevas malas prácticas electorales siguen siendo comunes.

Los estudios empíricos sobre la calidad de las elecciones y, más recientemente, sobre la integridad electoral han producido evidencia sobre el tipo de irregularidades y malas prácticas que se presentan con mayor frecuencia en América Latina. ${ }^{29}$ La percepción pública sobre las elecciones en la región parece confirmar algunos de estos hallazgos. Las deficiencias más destacadas en materia de instituciones políticas muestran el panorama crítico que aún persiste en la mayoría de los países de la región en lo que atañe a la confianza en las instituciones, el estado de derecho y la corrupción. Lo que se presenta a continuación es un panorama general de estos factores que moldean el contexto en el cual los actores valoran los costos que imprimen las leyes electorales a las malas prácticas y conductas indeseables.

En términos generales, América Latina es una región donde hay una clara percepción negativa de las principales instituciones de representación. Como se puede apreciar en la gráfica 1, instituciones como el Congreso y los partidos políticos -los principales actores encargados de diseñar y aprobar las legislaciones nacionales- gozaron de muy poca confianza entre la ciudadanía durante el periodo estudiado. En este sentido, resulta llamativo que la institución presidencial tuvo una mejor percepción de confianza en comparación con las mencionadas anteriormente en el contexto de la mayoría de casos analizados.

29 Véase Susan D. y Nikolay Marinov, Codebook for National Elections Across Democracy and Autocracy (NELDA), Nueva York, Yale University Press, 2011. Otra fuente de información es la "Encuesta a expertos sobre percepciones de integridad electoral” (PEI, por sus siglas en inglés) de Pippa Norris (op.cit., pp. 84-85 y 104). También está el Índice de Malas Prácticas Electorales (IEM), de Sarah Birch (op. cit., p. 48), el cual se ideó a partir de informes de las misiones de observación de las elecciones llevadas a cabo entre 1995 y 2007 en cuatro regiones del mundo. 


\section{GRÁFICA 1}

Desconfianza en las instituciones en América Latina

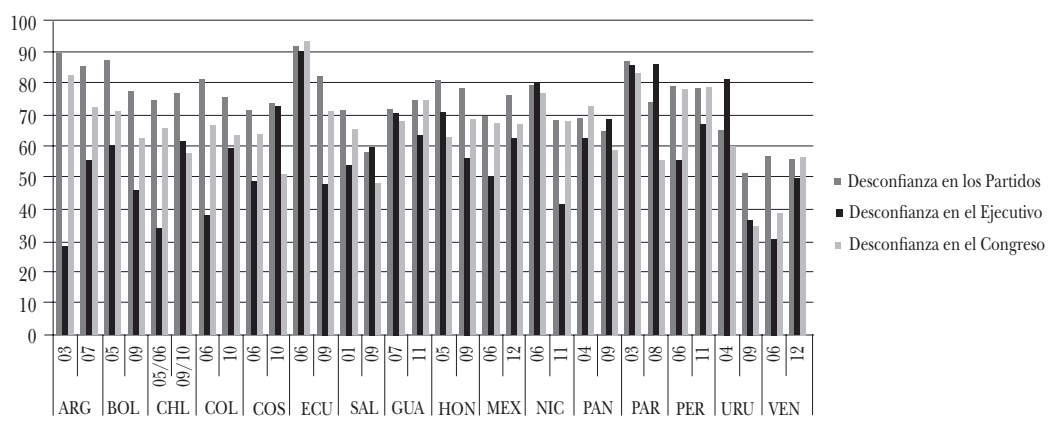

Fuente: la autora, con datos obtenidos del Latinobarómetro.

Comparativamente, destaca que Uruguay, Costa Rica y, en menor medida, Chile, muestren percepciones que contrastan con el resto de países latinoamericanos. Por ejemplo, en el caso uruguayo tanto el presidente como el congreso tienen una confianza superior al 50\%, situación similar a lo que ocurre con el congreso en Costa Rica y Chile. Sin embargo, cuando se promedian los niveles de desconfianza que tiene la ciudadanía con respecto de los partidos, del presidente y del Congreso, la percepción que predomina es negativa, lo que fortalece la idea de que la ciudadanía latinoamericana no tiene una buena imagen y confianza de sus instituciones representativas.

Uno de los factores que muestra una situación crítica en América Latina es el estado de derecho, esto es la capacidad de las instituciones para regirse por un sistema de leyes y a la vez para hacer prevalecer la ley, su acceso y justo ejercicio en la población. A partir del cruce de los indicadores de gobernanza del Banco Mundial sobre el estado de derecho y el control de la corrupción, se percibe que estas dos esferas se retroalimentan y que entre más débil es el estado de derecho, menor capacidad tiene de controlar la corrupción. A su vez, un estado de derecho sólido está vinculado con un mayor control de la corrupción. En este sentido, la gráfica 2 muestra que Uruguay, Chile y Costa Rica tienen una amplia evolución en 
la materia. Comparativamente, se observa un estado de derecho consolidado y un fuerte combate a la corrupción, lo que contribuiría a que tanto la ciudadanía como los actores políticos reconozcan y acepten que los costos de incurrir en prácticas que vulneren la legalidad son altos y, por supuesto, superiores al hecho de no hacerlo. Los actores aceptan, pues, que la probabilidad de ser castigados en un contexto de estado de derecho sólido es muy alta, mientras que en un contexto de estado de derecho frágil o débil es muy baja, lo cual refuerza el sentido de los incentivos generados por las normas.

\section{GRÁFICA 2}

Correlación entre percepciones de la corrupción y calidad del estado de derecho

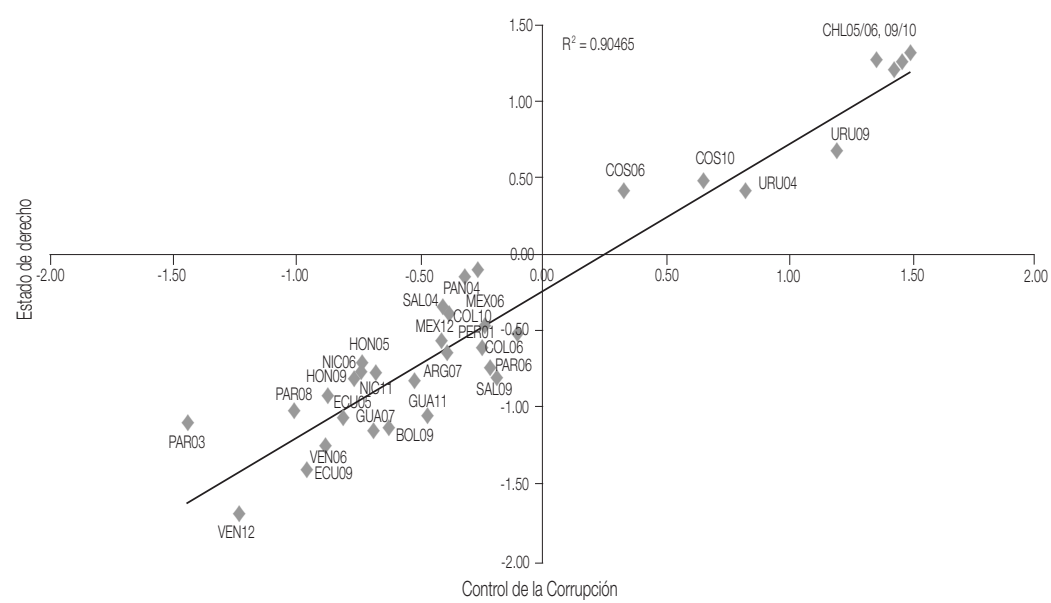

Fuente: la autora, con datos obtenidos de The Worldwide Governance Indicators del Banco Mundial.

Finalmente, se presentan los datos sobre la percepción de la limpieza de las elecciones. Los datos del Latinobarómetro muestran que en países como Costa Rica, Uruguay y Chile la mayor parte de la ciudadanía percibe que las elecciones que se celebran en su país 
han sido limpias y se observa lo contrario en el resto de los países de la región. Esto sugiere que pese a la celebración de elecciones que cumplen en términos generales con los requisitos de elecciones democráticas y las alternancias en el poder, las malas prácticas electorales no han desaparecido e influyen negativamente en la percepción de las elecciones y en la valoración de la ley y los incentivos que pretende propiciar.

GRÁFICA 3

Percepción de las elecciones en América Latina.

Limpias vs. fraudulentas

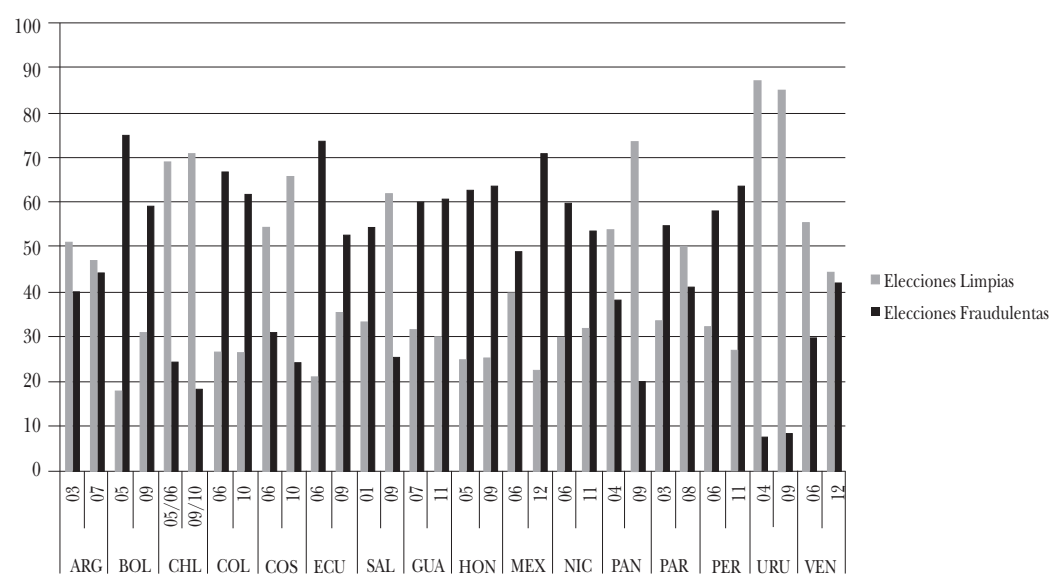

Fuente: la autora, con datos obtenidos del Latinobarómetro.

Los elementos del contexto presentados sugieren que, pese a los grandes avances logrados en materia de organización electoral y opciones presentadas al electorado, por mencionar algunos cambios, persisten condiciones muy desfavorables para la consolidación de la democracia en algunos países de la región, como la desconfianza en el Congreso y en los partidos, un débil estado de derecho y una franca desconfianza en la limpieza de las elecciones mismas. 


\section{LA APLICACIÓN DEL MARGO ANALÍTICO: LAS ELEGCIONES} EN AmÉrica LATINA

Los intentos de medición de las malas prácticas electorales enfrentan grandes desafíos. Su carácter oculto y adaptación permanente a nuevas circunstancias hacen muy difícil su seguimiento, la identificación de su naturaleza y, particularmente, la determinación de sus dimensiones e impacto. A ello se agrega el reto de la validez de las mediciones. La bibliografía al respecto afirma que los investigadores toman decisiones complejas para conectar las ideas con los hechos. Según Adcock y Collier, la validez de la medición está especialmente preocupada por si la operacionalizacion y codificación o calificación refleja adecuadamente el concepto que el investigador busca medir. ${ }^{30}$ Ellos sugieren tres formas para evaluar la validez de la medición: contenido, validación convergente (convergent/discriminant) y validación nomológica (nomological/construct). Este artículo se concentra en la primera forma de validez que se refiere a la 'adecuación de contenido', es decir, el grado en que un indicador dado captura adecuadamente el contenido completo del concepto sistematizado. ${ }^{31}$

Según lo anterior, se presenta a continuación la aplicación del marco analítico al problema de las leyes electorales en América Latina en el periodo comprendido entre 2000 y 2012. El propósito es mostrar en qué medida los indicadores de los costos que imprime la ley a las malas prácticas -lo que la ley prohíbe y castiga- capturan el contenido del concepto sistematizado, que en este caso es la manipulación estratégica del diseño de las leyes electorales. En primer lugar, se muestra el resultado de la codificación de las leyes electorales según un criterio dicotómico simple Sí/No que permite diferenciar la medida en que las leyes electorales prohíben y castigan las malas prácticas electorales siguientes: uso de recursos

30 "Measurement validity: A Shared Standard for Qualitative and Quantitative Research”, American Political Science Association, vol. 95, núm. 3, 2001, p. 529.

${ }^{31}$ La validación convergente mide el grado en que las calificaciones obtenidas de indicadores alternativos de un concepto dado están empíricamente asociadas y son convergentes, mientras que la validación nomológica evalúa el desempeño de los indicadores en relación con las hipótesis causales. Véase loc. cit. 
del Estado, cobertura sesgada de medios, rebase de topes de campaña y partidismo de los órganos electorales. En segundo lugar, se presenta el resultado de la calificación de las leyes con base en una escala de valores que van del 1 al 7, en la cual 1 representa el menor grado de manipulación, esto es una ley que contiene una prohibición clara y específica de la conducta no deseada y al mismo tiempo castigos también claros y específicos, y 7, el mayor grado de manipulación, esto es una ley que no prohíbe y no castiga en absoluto la conducta en cuestión. Este segundo ejercicio analítico permite hacer comparaciones entre leyes y países y además apreciar el cambio en el tiempo, lo cual, a su vez, hace posible identificar grupos de países en situaciones similares.

El análisis y codificación del contenido de las leyes electorales se realizó con base en los siguientes criterios: $a$ ) la fuente sustantiva de información con respecto de las prohibiciones y castigos se constituye de la ley electoral o código electoral de cada país vigente durante las elecciones presidenciales del periodo estudiado y, en su caso, de otras leyes en la materia -leyes de partidos políticos, de participación ciudadana, de delitos electorales, entre otras, mismas que están enlistadas en el apéndice que acompaña este texto-; b) se valoró el grado en que la ley señala claramente la conducta punible; y $c$ ) se valoró el grado en el que la ley señala claramente el castigo. El cuadro 5 muestra una matriz de la situación general de las leyes electorales según el criterio dicotómico simple mencionado anteriormente:

\section{Cuadro 5}

La manipulación del diseño de las leyes electorales en América Latina entre los años 2000 y 2012: dimensión de iure y de facto

\begin{tabular}{|c|c|c|c|c|c|c|c|c|c|}
\hline \multirow[t]{2}{*}{ País } & \multirow[t]{2}{*}{ Año } & \multicolumn{2}{|c|}{$\begin{array}{c}\text { Uso de recursos } \\
\text { públicos }\end{array}$} & \multicolumn{2}{|c|}{$\begin{array}{c}\text { Cobertura sesgada } \\
\text { de medios }\end{array}$} & \multicolumn{2}{|c|}{$\begin{array}{c}\text { Topes de gastos } \\
\text { de campaña }\end{array}$} & \multicolumn{2}{|c|}{$\begin{array}{c}\text { Partidismo órgano } \\
\text { electoral }\end{array}$} \\
\hline & & Prohíbe & Castiga & Prohíbe & Castiga & Prohíbe & Castiga & Prohíbe & Castiga \\
\hline ARG & 2003 & $\mathrm{NO}$ & $\mathrm{NO}$ & $\mathrm{NO}$ & $\mathrm{NO}$ & NO & $\mathrm{NO}$ & NO & $\mathrm{NO}$ \\
\hline ARG & 2007 & NO & $\mathrm{NO}$ & $\mathrm{NO}$ & NO & SÍ & SÍ & NO & $\mathrm{NO}$ \\
\hline BOL & 2005 & SÍ & SÍ & SÍ & SÍ & NO & $\mathrm{NO}$ & SÍ & SÍ \\
\hline BOL & 2009 & SÍ & SÍ & SÍ & SÍ & $\mathrm{NO}$ & $\mathrm{NO}$ & SÍ & SÍ \\
\hline
\end{tabular}


Cuadro 5 (concluye)

\begin{tabular}{|c|c|c|c|c|c|c|c|c|c|}
\hline \multirow{2}{*}{$\begin{array}{l}\text { País } \\
\mathrm{CHI}\end{array}$} & \multirow{2}{*}{$\begin{array}{c}\text { Año } \\
2005\end{array}$} & \multicolumn{2}{|c|}{$\begin{array}{l}\text { Uso de recursos } \\
\text { públicos }\end{array}$} & \multicolumn{2}{|c|}{$\begin{array}{c}\text { Cobertura sesgada } \\
\text { de medios }\end{array}$} & \multicolumn{2}{|c|}{$\begin{array}{c}\text { Topes de gastos } \\
\text { de campaña }\end{array}$} & \multicolumn{2}{|c|}{$\begin{array}{c}\text { Partidismo órgano } \\
\text { electoral }\end{array}$} \\
\hline & & SÍ & SÍ & NO & NO & SÍ & SÍ & SÍ & SÍ \\
\hline CHI & 2009 & SÍ & SÍ & $\mathrm{NO}$ & NO & SÍ & SÍ & SÍ & SÍ \\
\hline $\mathrm{COL}$ & 2006 & SÍ* & SI'* & SÍ & $\mathrm{NO}$ & SI'* & NO & SÍ & SÍ \\
\hline $\mathrm{COL}$ & 2010 & SÍ* & SÍ & SÍ & $\mathrm{NO}$ & SÍ* & $\mathrm{NO}$ & SÍ & SÍ \\
\hline $\mathrm{CR}$ & 2006 & SÍ & SÍ & SÍ & $\mathrm{NO}$ & NO & NO & NO & NO \\
\hline CR & 2010 & SÍ & SÍ & SÍ* & NO & NO & NO & SÍ & SÍ \\
\hline ECU & 2006 & NO & NO & NO & $\mathrm{NO}$ & NO & NO & SÍ* & SÍ* \\
\hline ECU & 2009 & SÍ & SÍ & SI'* & SÍ & SÍ & SÍ & SÍ & SÍ \\
\hline SAL & 2004 & SÍ & SÍ & SI'* & SÍ* & NO & NO & SÍ* & SÍ* \\
\hline SAL & 2009 & SÍ & SÍ & SÍ & SÍ* & NO & NO & SÍ* & SÍ \\
\hline GUA & 2007 & SÍ & NO & NO & $\mathrm{NO}$ & NO & NO & NO & NO \\
\hline GUA & 2010 & SÍ & NO & $\mathrm{NO}$ & $\mathrm{NO}$ & SI & $\mathrm{NO}$ & NO & NO \\
\hline $\mathrm{HON}$ & 2005 & SÍ & SI'* & SI'* & NO & NO & $\mathrm{NO}$ & SÍ* & SI'* \\
\hline $\mathrm{HON}$ & 2009 & SÍ & SI'* & SÍ & SÍ* & SÍ & SÍ & SÍ* & NO \\
\hline MEX & 2006 & SÍ & SÍ & NO & $\mathrm{NO}$ & SÍ & SÍ & SÍ* & NO \\
\hline MEX & 2012 & SÍ & SÍ & SÍ* & SÍ* & SÍ & SÍ & SÍ* & $\mathrm{NO}$ \\
\hline NIC & 2006 & SÍ & SÍ & NO & $\mathrm{NO}$ & NO & NO & SÍ* & NO \\
\hline NIC & 2011 & SÍ & SÍ & NO & $\mathrm{NO}$ & $\mathrm{NO}$ & NO & SÍ* & NO \\
\hline PAN & 2004 & SÍ & NO & NO & NO & NO & NO & SÍ & SÍ \\
\hline PAN & 2009 & SÍ & SÍ & $\mathrm{NO}$ & $\mathrm{NO}$ & NO & $\mathrm{NO}$ & SÍ & SÍ \\
\hline PARG & 2003 & NO & NO & SÍ & NO & NO & NO & SÍ & NO \\
\hline PARG & 2008 & NO & NO & SÍ & NO & NO & NO & SÍ & NO \\
\hline PERÚ & 2006 & SÍ & SÍ & $\mathrm{NO}$ & $\mathrm{NO}$ & NO & NO & NO & NO \\
\hline PERÚ & 2011 & SÍ & SÍ & $\mathrm{NO}$ & $\mathrm{NO}$ & NO & $\mathrm{NO}$ & NO & NO \\
\hline URU & 2004 & SÍ & SÍ & NO & NO & NO & NO & SÍ & NO \\
\hline URU & 2009 & SÍ & SÍ & $\mathrm{NO}$ & $\mathrm{NO}$ & NO & NO & SÍ & NO \\
\hline VEN & 2006 & SÍ* & SI* & NO & NO & SÍ* & SÍ & SÍ & SÍ \\
\hline VEN & 2012 & NO & NO & SÍ & $\mathrm{NO}$ & $\mathrm{NO}$ & NO & SÍ & NO \\
\hline $\begin{array}{l}\% \text { SÍ p } \\
\text { y castig }\end{array}$ & rohíbe & $81.2 \%$ & $71.8 \%$ & $34.3 \%$ & $25 \%$ & $46.8 \%$ & $21.8 \%$ & $78.1 \%$ & $46.8 \%$ \\
\hline
\end{tabular}

Nota: el SÍ* se refiere a leyes que incluyen algún grado de prohibición, pero cuya ambigüedad permite varias interpretaciones y abre espacios de discrecionalidad amplios. Fuente: la autora, con base en las leyes electorales o códigos electorales de cada país. 
Según se observa en el cuadro 5, hay una importante heterogeneidad entre las leyes electorales de los países de la región, aunque las diferencias son aún mayores entre áreas temáticas. En el caso del uso de recursos públicos destaca una marcada tendencia a incluir la prohibición expresa de usar, con fines políticos o electorales, recursos, bienes y tiempo por parte de funcionarios públicos para favorecer a algún partido o candidato. Los castigos incluyen: remoción del cargo, inhabilitación, pago de multas y cárcel, entre otros. En general, hay un patrón claro en la normatividad electoral en esta área. De 32 leyes electorales analizadas (dos por país), sólo 6 no incluyen la prohibición expresa del uso de recursos públicos, y sólo 9 omiten los castigos correspondientes.

Otra área donde domina el consenso es la de los órganos electorales en la que ha habido una fuerte tendencia hacia el establecimiento de comisiones electorales independientes en la región. Si bien esto representa un avance considerable, las normas globales, acuerdos internacionales y códigos de las mejores prácticas mundiales sugieren incorporar expresamente en la ley la prohibición de los miembros de los órganos de administración electoral para favorecer a algún partido o candidato. En este sentido, es de observar que 25 legislaciones electorales de 32 ya incorporan la prohibición del partidismo, lo cual vale decir que su obligación es ser imparciales, pero sólo 15 incorporan sanciones a la violación de esta norma, con lo que reducen los costos de violar la norma e inclinar las decisiones a favor de algún partido.

En el caso de la cobertura de medios, parece haber menos consenso respecto a las normas globales y principios internacionales de elecciones con integridad. Como se muestra en el cuadro 5, en 17 legislaciones electorales no se prohíbe la cobertura sesgada de los medios a favor de algún partido o candidato, lo que sugiere que es un área donde hay un fuerte desacuerdo con respecto de los incentivos que deben crear las normas y, por tanto, los costos de las malas prácticas electorales. El cuadro 6 muestra la distribución de países en los cuatro escenarios posibles de la combinación de prohibición y castigos. Como se observa en el cuadro, la mayoría de los casos se encuentra en el segmento donde hay más manipula- 
ción del diseño de la ley, es decir donde la ley no prohíbe ni castiga la cobertura sesgada de medios:

\section{Cuadro 6}

Relaciones entre prohibiciones y castigos en la legislación electoral con respecto de la cobertura sesgada de medios informativos

\begin{tabular}{cll}
\hline & \multicolumn{1}{c}{$\begin{array}{c}\text { Sí hay castigos señalados en la } \\
\text { legislación electoral }\end{array}$} & \multicolumn{1}{c}{$\begin{array}{c}\text { No hay castigos señalados en la } \\
\text { legislación electoral }\end{array}$} \\
\hline $\begin{array}{c}\text { Sí hay prohibición } \\
\text { explícita en la }\end{array}$ & Casos: & Casos: \\
legislación electoral & Bolivia, 2005 y 2009, Ecuador, \\
& $2009 ; *$ El Salvador, 2004* & Colombia, 2006 y 2010; Costa \\
& y 2009;* Honduras, 2009;* & Rica, 2006* y 2010;* Honduras, \\
& México, 2012.* & 2005; Paraguay, 2003 y 2008; \\
No hay prohibición & & Casos: \\
explícita en la & & \\
legislación electoral & & Argentina, 2003 y 2005; Chile, \\
& & 2005 y 2009; Ecuador, 2006; \\
& Guatemala, 2007 y 2010; México, \\
& $2006 ;$ Nicaragua, 2006 y 2011; \\
& Panamá, 2004 y 2009; Perú, 2006 \\
& y 2011; Uruguay, 2004 y 2009; \\
& Venezuela, 2006. \\
\hline
\end{tabular}

*Hay leyes con algún grado de prohibición, pero cuya ambigüedad permite varias interpretaciones y abre espacios de discrecionalidad amplios.

Fuente: la autora, con información obtenida de la revisión de la legislación electoral de los países mencionados.

Otra de las áreas críticas de las elecciones democráticas es la de los gastos de campaña. Según se mencionó en la sección anterior, los organismos internacionales han destacado la necesidad de incorporar normas claras en cuanto al financiamiento de las campañas políticas y, en particular, en cuanto a los gastos y su informe puntual a la autoridad electoral. Una de las recomendaciones más enfáticas ha sido el establecimiento de topes de gastos de campaña 
para evitar, en la medida de lo posible, que candidatos y partidos gasten en forma desproporcionada, obtengan financiamiento de fuentes prohibidas o incluso incurran en conductas ilícitas, como la compra y coacción del voto.

Según se observa adelante en el cuadro 7, que muestra la distribución de países en los escenarios posibles de la relación entre prohibiciones y castigos, hay 21 leyes electorales que no establecen topes de gastos de campaña y, en consecuencia, no contemplan castigos, lo que sugiere que es una de las áreas estratégicas para los actores políticos -gobiernos, partidos, candidatos- quienes buscan evitar prohibiciones que los limiten en la búsqueda y ejercicio de recursos durante las campañas, prohibiciones que elevan los costos de violar las normas y hasta los costos de conseguir financiamiento.

En términos generales, parece claro que los actores políticos y, en particular, los gobiernos son estratégicos al momento de diseñar el contenido de las leyes electorales, pues no aplican el mismo estándar normativo en todas las áreas o etapas del ciclo electoral. Muestra de ello es que, como se presenta en los cuadros 6 y 7 , casi todos los países de la región prohíben el uso de recursos públicos para fines políticos y electorales y contemplan castigos para el incumplimiento de esa norma. Sin embargo, en el caso de los medios de comunicación y más aún de los gastos de campaña, predomina la tendencia a disminuir los costos de las malas prácticas electorales por medio de leyes que incluyen pocas o nulas prohibiciones y castigos para aquellos involucrados en la cobertura de medios sesgada y el rebase de topes de campaña.

Ahora bien, ¿cómo comparar entre leyes y países y, además, apreciar el cambio entre áreas y en el tiempo, a partir del análisis del contenido de la ley? La gráfica 4 (cf. infra) muestra la evolución del grado de manipulación del diseño de las leyes electorales en términos agregados en el periodo comprendido entre 2000 y 2012. Según puede verse en la gráfica, el diseño manipulador no es un evento extraordinario en América Latina. La calificación representa el promedio simple de los puntajes obtenidos en las cuatro áreas calificadas: recursos del Estado, medios de comunicación, gastos de campaña y órganos electorales. Tal promedio forma lo que llamo el grado de manipulación de la ley electoral. 


\section{Cuadro 7}

Relación entre prohibiciones y castigos en la legislación electoral con respecto del rebase de los topes de campaña

\begin{tabular}{|c|c|c|}
\hline & $\begin{array}{c}\text { Si hay castigos señalados en la } \\
\text { legislación electoral }\end{array}$ & $\begin{array}{c}\text { No hay castigos señalados en la } \\
\text { legislación electora }\end{array}$ \\
\hline $\begin{array}{l}\text { Sí hay prohibición } \\
\text { explícita en la }\end{array}$ & Casos: & Casos: \\
\hline legislación electoral & $\begin{array}{l}\text { Argentina, 2007; Chile, } 2005 \text { y } \\
\text { 2009; Ecuador, 2009; Honduras, } \\
\text { 2009; México, 2006 y 2012; } \\
\text { Venezuela, 2006.* }\end{array}$ & $\begin{array}{l}\text { Colombia, } 2006 * \text { y } 2010 ; * \\
\text { Guatemala, } 2010 .\end{array}$ \\
\hline $\begin{array}{l}\text { No hay prohibición } \\
\text { explícita en la }\end{array}$ & & Casos: \\
\hline legislación electoral & & $\begin{array}{l}\text { Argentina, 2003; Bolivia, } 2005 \\
\text { y 2009; Costa Rica, } 2006 \text { y 2010; } \\
\text { Ecuador, 2006; El Salvador, } \\
2004 \text { y 2009; Guatemala, 2007; } \\
\text { Honduras, 2005; Nicaragua, } \\
2006 \text { y 2011; Panamá, } 2004 \text { y } \\
\text { 2009; Paraguay, 2003 y 2008; } \\
\text { Perú, 2006 y 2011; Uruguay, } \\
2004 \text { y 2009; Venezuela, } 2012 .\end{array}$ \\
\hline
\end{tabular}

*Hay leyes con algún grado de prohibición, pero cuya ambigüedad permite varias interpretaciones y abre espacios de discrecionalidad amplios.

Fuente: la autora, con información obtenida de la revisión de la legislación electoral de los países mencionados.

Chile es uno de los países que contempla prohibiciones y castigos claros en tres de las áreas estudiadas, a saber: uso de recursos públicos, topes de gastos de campaña y partidismo del órgano electoral. El puntaje promedio obtenido es de 2.75 para la ley vigente en la elección presidencial de 2005 y de 2.5 en la de 2009 , pues en esta última se incorporó una modificación en la ley respecto al partidismo de los órganos electorales, lo que afectó positivamente su promedio. En ambas elecciones, la calificación corresponde a una manipulación baja del diseño de sus leyes electorales según el marco analítico propuesto que contempla una escala del 1 al 7 , 
donde 1 representa el nivel más bajo de manipulación y 7, el más alto. Bolivia también contempla prohibiciones y castigos en el uso de recursos públicos, cobertura sesgada de medios y partidismo del órgano electoral en su legislación vigente en esas mismas elecciones. Sin embargo, no incluye topes de campaña ni castigos aplicables en la materia, por lo que en términos agregados tiene un nivel medio bajo de manipulación de sus leyes. El promedio obtenido es de 3, pues la precisión (o aplicabilidad de la ley) es menor con respecto de Chile. Aquí vale la pena notar que la escala de valores aplicada a la calificación de las leyes efectivamente logra capturar los cambios en la ley y la medida en que las normas son más precisas en las prohibiciones y castigos y, por tanto, en los costos que imprime a los actores políticos transgresores.

\section{GRÁFICA 4}

Manipulación del marco legal electoral en América Latina entre 2000 y 2012

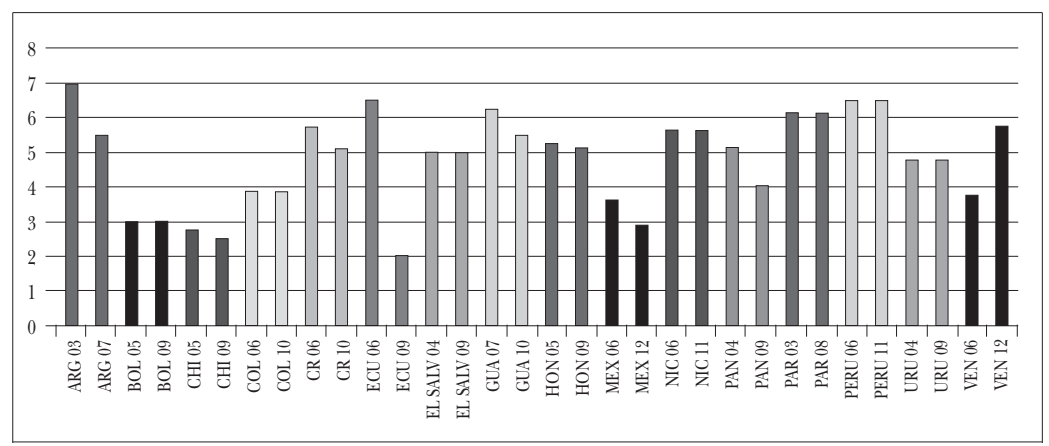

Nota: La escala va del 1 al 7, donde 1 representa el nivel más bajo de manipulación y 7, el más alto.

Fuente: la autora, con datos de leyes electorales de cada país.

En el otro lado de la escala, hacia el nivel más alto de manipulación del diseño de las leyes electorales y con escaso cambio en el periodo 2000-2012, se encuentran Paraguay, Perú y Nicaragua. Ninguno de los tres contempla topes de campaña en sus marcos legales 
electorales y los dos últimos -Perú y Nicaragua- tampoco incluyen prohibiciones claras ni castigos a los sesgos en la cobertura de los medios de comunicación y al partidismo de los órganos electorales. Según la escala aplicada del 1 al 7, tienen un grado mayor de manipulación de su marco legal electoral con un promedio de 6.5 en el caso de Perú y de 5.6 en el caso de Nicaragua. Así, al no prohibir ni castigar las malas prácticas electorales, las legislaciones de estos países bajan los costos políticos y de legitimidad por llevarlas a cabo.

Los casos relativamente exitosos en materia de reforma de las leyes electorales son los de Ecuador, Argentina, Panamá, Costa Rica y México, que contaban con leyes electorales alta o medianamente manipuladas al comienzo del periodo y finalizan en el nivel bajo de manipulación. Esto significa que incluyeron prohibiciones y castigos en diversas áreas del proceso electoral. El caso más extraordinario es el de Ecuador, que pasa de un promedio de 6.5 en su ley vigente en la elección de 2006 a un promedio de 2 en su ley de 2009, lo que significa que elevó paulatinamente los costos de las malas prácticas electorales. En estos casos es importante mirar el contexto y valorar en qué medida el valor relativo de los costos que imprime la ley se desvanecen en un contexto de fragilidad del estado de derecho.

Un caso dramático es Venezuela. La ley electoral de 2006 se situaba en el rango medio de la escala, pues incluía prohibiciones y castigos claros al partidismo en los órganos electorales y más generales (o ambiguos) en el uso de recursos públicos y en topes de campaña. En su ley electoral de 2012, eliminó totalmente las prohibiciones en el uso de recursos públicos y topes de campaña, y parcialmente en cobertura de medios y el partidismo del órgano electoral, con lo que alcanzó un grado alto de manipulación con una calificación de 5.75 en la escala 1-7.

México es el tercer país mejor posicionado en relación con la prohibición explícita de malas prácticas electorales. La ley electoral de México ha sido reformada varias veces -en 1990, 1993, 1996, 2008 y más recientemente en 2014. Estas modificaciones legislativas han permitido transitar de elecciones en las que el fraude era abierto a procesos electorales democráticos y organizados por un organismo electoral independiente, aunque en su 
vertiente híbrida. ${ }^{32}$ El Instituto Nacional Electoral -hasta 2014 Instituto Federal Electoral- ha sido ampliamente reconocido por su profesionalismo, pero igualmente criticado por no sancionar las malas prácticas de partidos políticos durante algunas elecciones. ${ }^{33}$

Uruguay es claramente un caso especial, pues incluye prohibiciones en dos áreas, la del uso de recursos públicos y el partidismo del órgano electoral, pero no contiene prohibición alguna en las dos áreas más críticas del proceso electoral, el caso de los medios de comunicación y los topes de campaña. Para Kevin Casas-Zamora, esto no es el resultado de un comportamiento ejemplar de los partidos y candidatos, sino la ilustración de las partes evitando la regulación. ${ }^{34}$ En cualquier caso, de nueva cuenta se vuelve importante señalar el valor relativo de los costos según el contexto, de manera que en Uruguay, con una mayor confianza en las instituciones políticas y un sólido estado de derecho, la ausencia de prohibiciones y castigos no necesariamente significa costos nulos.

Entonces, ¿qué tanto depende el valor relativo de los costos que imprime la ley electoral del contexto? La siguiente gráfica explora

${ }^{32}$ R. López Pintor (Administración electoral y consolidación democrática, Lima, Asociación Civil Transparencia-International IDEA, 2004) señala que el IFE (ahora INE) es un órgano electoral híbrido, pues tiene un componente de independencia ligado al profesionalismo y al mérito, y otro político, en la medida en que sus miembros son electos por el Congreso.

${ }^{33}$ Un ejemplo del sesgo en los órganos electorales y la falta de aplicación de sanciones es la distribución masiva de tarjetas llamadas "la cumplidora", con que los candidatos locales en las elecciones estatales entre 2012 y 2013 ofrecían beneficios futuros a cambio del voto, canjeables sólo si el candidato resultaba ganador. Los organismos locales, y después el federal, aceptaron la "legalidad" de dicha práctica, pese a que la ley prohíbe y castiga expresamente la compra de votos y el condicionamiento de programas sociales.

${ }^{34}$ Casas-Zamora ("State Funding and Campaign Finance Practices in Uruguay", en Eduardo Posada-Carbó y Carlos Malamud (eds.), The Financing of Politics: Latin American and European Perspectives, Londres, Institute for the Study of the Americas, 2005) afirma que "si el financiamiento de las campañas políticas está lejos de ser transparente en la mayoría de los países, es un asunto decididamente secreto en Uruguay. A pesar de varios intentos de regularlos desde el retorno de la democracia en 1984, las actividades de recaudación de fondos de los partidos uruguayos y sus sectores internos innumerables permanecen privados de cualquier control externo". 
la relación entre el estado de derecho, medido por los indicadores de gobernanza del Banco Mundial y la manipulación del diseño de las leyes electorales, a partir de la calificación promedio presentada anteriormente.

GRÁFICA 5

Calidad del estado de derecho y manipulación del marco legal electoral

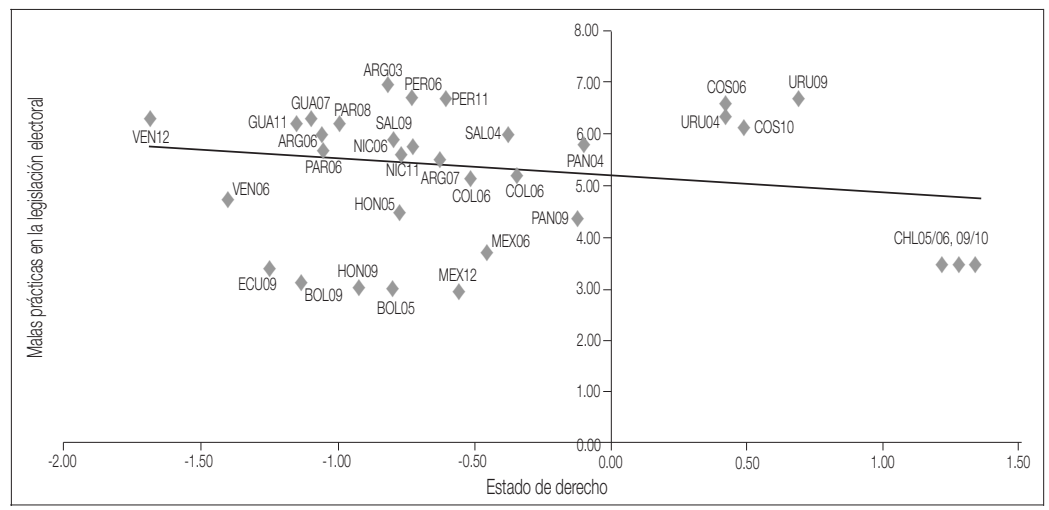

Según se observa, aunque el índice de correlación de Pearson es bajo, la gráfica muestra una tendencia clara de asociación entre un estado de derecho sólido y una menor manipulación de la ley como en Chile, Costa Rica y Uruguay. Y al mismo tiempo, una relación entre un estado de derecho frágil y una mayor tendencia a disminuir los costos de las malas prácticas con prohibiciones y castigos laxos o inexistentes.

Un ejemplo de manipulación del diseño de la ley Perú.

La aprobación de la Ley de Partidos Políticos en 2003

El proceso de negociación de la Ley de Partidos Políticos de Perú, aprobada y promulgada en 2003 y que actualmente sigue vigente, es un ejemplo de cómo los actores políticos deciden disminuir los 
costos de ciertas prácticas a partir de la inclusión o no de prohibiciones y castigos o espacios de discrecionalidad para premiar o castigar a partidos. En el caso de esa elección, el presidente de Perú, Alejandro Toledo, y su partido, Perú Posible, representaban la primera fuerza política en el Congreso. Después de más de veinte propuestas para crear una Ley de Partidos Políticos, tanto el gobierno, como el congreso, decidieron avanzar para crear un marco de regulación en aspectos relevantes como la vida interna y el financiamiento de las organizaciones políticas. Como resultado del proceso de negociación de la reforma, quedó establecido un modelo mixto de financiamiento para las actividades ordinarias y de campaña que permite recursos públicos y privados, cada uno sometido a una regulación específica. Sin embargo, el entonces presidente y su bancada en el Congreso limitaron el acceso de recursos públicos a los partidos de oposición, sometiendo a la interpretación del propio titular del ejecutivo la tercera disposición transitoria de la ley, la cual expresamente señala que este financiamiento se entregará a condición de que haya presupuesto suficiente en la hacienda nacional.

Esta situación establecida en la ley ha traído como consecuencia acciones que representan un círculo vicioso de malas prácticas. Mientras para la oposición la búsqueda de más recursos privados se ha convertido en una prioridad, de tal manera que llegan a incurrir en el ocultamiento de estas aportaciones para evadir los topes de campaña y ser competitivos, para el partido en el gobierno ha abierto sospechas sobre el objetivo de las restricciones de financiamiento público a la oposición y la medida en que representan un incremento en los flujos de recursos públicos para su propio beneficio.

Una de las consecuencias del diseño manipulador de la Ley de Partidos Políticos es la disputa constante entre autoridades electorales y partidos políticos según las sanciones y multas financieras establecidas por diversos incumplimientos en materia de reporte de ingresos financieros. Lo anterior ha llevado, desde la perspectiva de los partidos opositores, a señalar que hay vulnerabilidad frente al gobierno y el partido en el poder dada la falta de recursos públicos que la autoridad gubernamental debería otorgarles, generando importantes restricciones presupuestales que limitan su competiti- 
vidad. Esta situación ha llevado a que el Jurado Nacional Electoral deba intervenir para llevar a juicio a distintas organizaciones políticas y así buscar que cumplan con las multas impuestas por la Oficina Nacional de Procesos Electorales. ${ }^{35}$

Para dar cuenta de la manipulación electoral estratégica a la que se hace referencia, resulta importante atender el proceso parlamentario que dio origen a la aprobación de la Ley de Partidos Políticos y a la composición del Congreso en aquel momento.

\section{Cuadro 8}

Conformación del congreso peruano en la etapa de aprobación de la Ley de Partidos Políticos

\begin{tabular}{cc}
\hline Partido & $N^{0}$ de escaños en el Congreso \\
\hline Partidos vinculados al Ejecutivo & \\
Perú Posible (Partido del Presidente) & 45 \\
Frente Independiente Moralizador FMI & 11 \\
Partidos de Oposición & \\
APRA & 28 \\
Unidad Nacional & 17 \\
UPP-SI & 6 \\
Somos Perú & 4 \\
Acción Popular & 3 \\
Cambio 90-Nueva Mayoría & 3 \\
Otros (1 cada uno) & 3 \\
Total & $\mathbf{1 2 0}$ \\
\hline
\end{tabular}

Fuente: la autora, con base en información del Archivo Digital de la Legislación del Perú del Congreso de la República.

${ }^{35}$ Recientemente, el Jurado Nacional de Elecciones decidió llevar a juicio a los partidos políticos que desde 2011 se han negado a cubrir el pago de las multas por violaciones a la legislación electoral en materia de financiamiento y propaganda electoral. Para ampliar el contexto se sugiere revisar el seguimiento que la prensa local ha dado al tema (http://larepublica.pe/impresa/politica/823318jne-judicializa-cobro-partidos-politicos-morosos), así como el informe de la misión de observación electoral de la oEA sobre las elecciones generales del Perú, primera y segunda vuelta, de la elección general de 2011. 


\section{Cuadro 9}

Votación de los artículos 28, 29 y 36 Inciso A de la Ley de Partidos Políticos en Perú, 2003 (en materia del modelo de financiamiento y barreras para los partidos de oposición)

\begin{tabular}{ccccc}
\hline Grupo Parlamentario & \multicolumn{5}{c}{ Sentido de la votación } \\
& A favor & En contra & Abstención & No responde \\
\hline Perú Posible & 28 & 2 & 2 & 1 \\
APRA & 0 & 20 & 0 & 1 \\
Unidad Nacional & 1 & 9 & 0 & 0 \\
FMI & 4 & 4 & 1 & 0 \\
SP-AO-UPP & 6 & 0 & 2 & 0 \\
Democrático & & & & \\
Independiente & 0 & 6 & 0 & 0 \\
Perú Ahora & 4 & 0 & 0 & 1 \\
No agrupados & 1 & 2 & 0 & 0 \\
Resultado de la votación & $\mathbf{4 4}$ & $\mathbf{4 3}$ & $\mathbf{5}$ & $\mathbf{3}$ \\
\hline
\end{tabular}

Fuente: la autora, con base en información del Archivo Digital de la Legislación del Perú del Congreso de la República.

\section{Cuadro 10}

Votación de la tercera disposición transitoria de la Ley de Partidos Políticos en Perú, 2003 (en materia de atribuciones para que el poder ejecutivo determine la disponibilidad de recursos para financiamiento público)

\begin{tabular}{ccccc}
\hline Grupo Parlamentario & \multicolumn{4}{c}{ Sentido de la votación } \\
& A favor & En contra & Abstención & No responde \\
\hline Perú Posible & 30 & 0 & 2 & 1 \\
APRA & 0 & 21 & 0 & 0 \\
Unidad Nacional & 1 & 7 & 1 & 1 \\
FMI & 5 & 2 & 2 & 0 \\
SP-AP-UPP & 5 & 0 & 2 & 1 \\
Democrático Independiente & 0 & 3 & 3 & 0 \\
Perú Ahora & 4 & 0 & 0 & 1 \\
No agrupados & 1 & 2 & 0 & 0 \\
Resultado de la votación & $\mathbf{4 6}$ & $\mathbf{3 5}$ & $\mathbf{1 0}$ & $\mathbf{4}$ \\
\hline
\end{tabular}

Fuente: la autora, con base en información del Archivo Digital de la Legislación del Perú del Congreso de la República. 
El cuadro 8 muestra la composición que tenía el congreso peruano durante la legislatura que aprobó la Ley de Partidos Políticos, mientras que los cuadros 9 y 10 presentan las votaciones y un enfrentamiento claro entre oposición y oficialismo en los temas señalados del modelo de financiamiento y los controles del ejecutivo sobre los recursos públicos. Sin embargo, al final los partidos vinculados al Presidente lograron la aprobación de dichas medidas en perjuicio de los partidos de oposición.

\section{Conclusiones}

Los procesos de democratización en el mundo no han suprimido del todo las malas prácticas electorales que erosionan la calidad de las elecciones, dañan la confianza de la sociedad en las instituciones y afectan la legitimidad de los gobiernos electos. Entre los diferentes tipos de manipulación, la del diseño del marco legal de las elecciones es particularmente relevante en América Latina.

Pese a haber avanzado en las investigaciones sobre este problema, persiste la falta de consenso sobre la forma de entenderlo, definirlo y estimarlo. En el presente texto se parte de que la medición de la manipulación del diseño del marco legal de las elecciones presenta múltiples retos. A la naturaleza opaca del proceso de diseño de las leyes, y la falta de datos y evidencia sistematizada sobre los intereses de los actores durante las negociaciones de las mismas, se suma el carácter contextual de las normas, es decir -siguiendo a Nohlen- los efectos de las instituciones son dependientes del contexto y, por tanto, de la configuración de otras variables con las cuales interactúan.

Frente a ello, la contribución de este trabajo es la presentación de un marco conceptual y la propuesta de estrategias empíricas para identificar el diseño manipulador de las leyes electorales. Ésta se tiene por el proceso mediante el cual los actores políticos dentro del sistema -principalmente los partidos y el gobierno de turno- promueven normas que disminuyen los costos asociados a las malas prácticas electorales por medio de prohibiciones y castigos laxos o inexistentes, cuyo valor relativo depende del contexto. 
Este marco se aplica al análisis de las leyes electorales de 16 países de América Latina en el periodo comprendido entre 2000 y 2012 en cuatro áreas críticas para la integridad de las elecciones: la cobertura de los medios de comunicación, los topes de campaña, los organismos electorales y el uso de los recursos del Estado.

El análisis realizado bajo el marco analítico propuesto mostró que, pese a la complejidad que representa la comparación de marcos legales electorales de diferentes países, hay patrones o tendencias que permiten advertir la disminución de costos asociados a ciertas malas prácticas electorales que evidencian la manipulación del diseño de la ley. En lo que toca al uso de recursos públicos y de órganos electorales casi todos los países analizados incluyen prohibiciones y castigos claros -siguiendo en gran medida las recomendaciones y estándares internacionales-, lo que aumenta el costo de llevar a cabo dicha conducta. Sin embargo, el valor relativo de dichos costos depende del contexto y, de manera particular, de factores como la fortaleza del estado de derecho que hace más o menos probable la aplicación de las sanciones contempladas en la ley.

Lo anterior contrasta con lo establecido por las leyes electorales de los países analizados en lo que atañe a topes de gastos de campaña y cobertura de medios, las leyes electorales que son en general omisas y tienden a no prohibir y a no castigar la cobertura sesgada de medios y el rebase. Con ello, no sólo disminuyen los costos de las malas prácticas mencionadas, sino que abren también el abanico de opciones disponibles y con ello la rentabilidad de las mismas. Ahora bien, como se mencionó anteriormente, el valor relativo de los costos asociados a prácticas como el rebase de topes de campaña o el sesgo partidista o político de los medios durante las campañas electorales y, por tanto, la capacidad de las normas para disuadir a los actores de llevarlas a cabo, depende del contexto y de factores como la confianza en las instituciones y la fortaleza del estado de derecho en cada uno de los países estudiados.

Así pues, la codificación y el análisis comparado de las leyes electorales de 16 países de América Latina en el periodo de 2000 a 2012 mostró que Chile y Bolivia, por ejemplo, contemplan prohibiciones y castigos claros en al menos tres de las áreas estudiadas, cuya violación representa un alto costo. Por tanto, ambos son ejem- 
plo de la baja manipulación del diseño de la ley, mientras que $\mathrm{Pa}$ raguay y Perú se colocan como los casos en lo que hay una alta manipulación del contenido de sus leyes, pues no incluyen prohibiciones claras ni castigos a los sesgos en la cobertura de los medios de comunicación y al partidismo de los órganos electorales ni tampoco se incluyen topes de campaña. Todo lo cual redunda en bajos costos de llevar a cabo las conductas que dañan o erosionan la integridad de las elecciones. Con todo, el valor relativo de los costos altos o bajos, según las prohibiciones y castigos que establecen las leyes electorales, depende del contexto de cada país. El análisis del contexto latinoamericano realizado en el presente texto mostró que hay un fuerte contraste entre países en lo que toca a la confianza en las instituciones -partidos, Ejecutivo y Congreso-, pero también en la percepción de la limpieza de las elecciones y la fortaleza del estado de derecho, todos ellos factores que influyen en el valor relativo de los costos que imprimen las leyes electorales por medio de prohibiciones y castigos de ciertas prácticas electorales.

Por lo que toca a los alcances metodológicos, la evidencia expuesta apoya la validez de la medición del marco analítico presentado en términos de su contenido, esto es del grado en que los indicadores logran capturar adecuadamente el contenido del concepto sistematizado de la manipulación del diseño de las leyes electorales. Una agenda futura debe incluir, sin duda, las dos formas adicionales de validación, la convergente y la nomológica. En términos temáticos, la investigación muestra la importancia de explorar los factores vinculados al fenómeno de las malas prácticas electorales, aquellos que expliquen por qué en algunos países se establecen prohibiciones y castigos y en otros no, y por qué en algunos casos estas normas sirven para desalentar la ejecución de malas prácticas electorales y en otros no.

\section{BibLIOGRAFÍA}

Adcock, Robert y David Collier, "Measurement validity: A Shared Standard for Qualitative and Quantitative Research", American Political Science Association, vol. 95, núm. 3, 2001, pp. 529-546. 
Álvarez, R. Michael y Frederick Boehmke, "Correlates of Fraud: Studying State Election Fraud Allegations”, en R. Michael Álvarez, Thad E. Hall y Susan D. Hyde (eds.), Election Fraud: Detecting and Deterring Electoral Manipulation, Washington, DC, Brookings Institution Press, 2008, pp. 99-111.

-, Thad E. Hall y Susan D. Hyde, "Introduction: Studying Election Fraud”, en R. Michael Álvarez, Thad E. Hall y Susan D. Hyde (eds.), Election Fraud: Detecting and Deterring Electoral Manipulation, Washington, DC, Brookings Institution Press, 2008, pp. 1-18.

y Thad E. Hall, Electronic Elections: The Perils and Promises of Digital Democracy, Nueva Jersey, NJ, Princeton University Press, 2010.

Birch, Sarah, "Perceptions of Electoral Fairness and Voter Turnout", Comparative Political Studies, vol. 43, núm. 12, 2010, pp. 1601-1622. , Electoral Malpractice, Oxford, University Press, 2011.

Casas-Zamora, Kevin, "State Funding and Campaign Finance Practices in Uruguay", en Eduardo Posada-Carbó y Carlos Malamud (eds.), The Financing of Politics: Latin American and European Perspectives, Londres, Institute for the Study of the Americas, 2005.

Catón, Matthias, Daniel Sabsay y Bernhard Thibaut, "La legislación electoral. Bases Legales, estatus, mecanismos de reforma”, en Dieter Nohlen, Daniel Zovatto, Jesús Orozco y José Thompson (comps.), Tratado de derecho electoral comparado de América Latina, México, F.C.E.Instituto Interamericano de Derechos Humanos-Universidad de Heidelberg-International IDEA-Tribunal Electoral del Poder Judicial de la Federación-Instituto Federal Electoral, $2^{a}$ ed., 2007.

Comisión Europea para la Democracia por el Derecho, Código de buenas prácticas en materia electoral. Directrices e informe explicativo, introd. de María del Carmen Alanis Figueroa, pról. de Gianni Buquicchio, México, Tribunal Electoral del Poder Judicial de la Federación, 2011.

Congreso de la República del Perú, Archivo Digital de la Legislación del Perú, en http://www.leyes.congreso.gob.pe/

Declaración de principios para la observación internacional de elecciones, acto de conmemoración celebrado en las Naciones Unidas, Nueva York, 27 de octubre de 2005.

Donsanto, Craig C., "Corruption of the Election Process under U.S. Federal Law”, en R. Michael Álvarez, Thad E. Hall y Susan D. Hyde (eds.), 
Election Fraud: Detecting and Deterring Electoral Manipulation, Washington, DC, Brookings Institution Press, 2008.

Elklit, Jorgen y Andrew Reynolds, "A Framework for the Systematic Study of Election Quality”, Democratization, vol. 12, núm. 2, 2005, pp. 147-162.

Fernández, Francisco S. y Fernando J. Ojesto, "Delitos y faltas electorales”, en Dieter Nohlen, Daniel Zovatto, Jesús Orozco y José Thompson (comps.), Tratado de derecho electoral comparado de América Latina, México, F.C.E.-Instituto Interamericano de Derechos Humanos-Universidad de Heidelberg-International IDEA-Tribunal Electoral del Poder Judicial de la Federación-Instituto Federal Electoral, 2a ed., 2007.

Goodwin-Gill, Guy S., Free and Fair Elections: International Law and Practice, Ginebra, Inter-Parliamentary Union, 1994.

Hartlyn, Jonathan, Jennifer McCoy y Thomas M. Mustillo, "La importancia de la gobernanza electoral y la calidad de las elecciones en la América Latina contemporánea”, América Latina Hoy, vol. 51, núm. 1, 2009, pp. 15-40.

Huntington, Samuel P., La tercera ola. La democratización a finales del siglo XX, trad. de Josefina Delgado, Barcelona, Paidós, 1994.

Hyde, Susan D. y Nikolay Marinov, Codebook for National Elections Across Democracy and Autocracy (NELDA), Nueva York, Yale University Press, 2011.

International IDEA: Institute for Democracy and Electoral Assistance, "Deepening Democracy: A Strategy for Improving the Integrity of Elections Worldwide", The Report of the Global Commission on Elections, Democracy and Security, 2012.

Langston, Joy, “Las reformas al Cofipe, 2007”, Política y gobierno, vol. temático, núm. 2, 2009, pp. 245-272.

Lehoucq Fabrice, "Electoral Fraud: Causes, types, and Consequences", Annual Review of Political Science, vol. 6, núm. 1, 2003, pp. 233-256.

-, "Bolivia's Constitutional Breakdown", Journal of Democracy, vol. 19, núm. 4, 2008, pp. 110-124.

Levine, Daniel H. y José E. Molina (eds.), The Quality of Democracy in Latin America, Boulder, Lynne Rienner Publishers, 2011.

Levitsky, Steven y Lucan Way, "Why Democracy Needs a Level Playing Field in Journal of Democracy", Journal of Democracy, vol. 21, núm. 1, 2010, pp. 57-68. 
Lijphart, Arend, Electoral Systems and Party Systems. A Study of Twenty-Seven Democracies, 1945-1990, Oxford, University Press, 1994.

López Pintor, Rafael, Administración electoral y consolidación democrática, Lima, Asociación Civil Transparencia-International IDEA, 2004.

March, James G. y Johan P. Olsen, "Elaborating the «New Institutionalism»", en Sarah A. Binder, R. A. W. Rhodes y Bert A. Rockman (eds.), Oxford Handbook of Political Institutions, Oxford, University Press, 2006.

Massicotte, Louis, André Blais y Antoine Yoshinaka (eds.), Establishing the Rules of the Game. Election Laws in Democracies, Toronto, University Press, 2004.

Morlino, Leonardo, "Anchors and Democratic Change", Comparative Political Studies, vol. 38, núm. 7, 2005, pp. 743-770.

—, Changes for Democracy: Actors, Structures, Processes, Oxford, University Press, 2012.

Norris, Pippa, "Are There Global Norms and Universal Standards of Electoral Integrity and Malpractice?", Comparing Public and Expert Perceptions, HKs Faculty Research Working Paper Series RWP12-010, Cambridge, MA, John F. Kennedy School of Government, Harvard University, 2012.

—, "The New Research Agenda Studying Electoral Integrity", Electoral Studies, vol. 34, núm. 4, 2013, pp. 563-575.

—, Why Electoral Integrity Matters, Cambridge, University Press, 2014.

North, Douglass C., "Institutions", The Journal of Economic Perspectives, vol. 5, num. 1, 1991, pp. 97-112.

Ortiz, Richard, "Contextos, instituciones y actores políticos: Dieter Nohlen y el estudio de las instituciones en América Latina", en Dieter Nohlen, El institucionalismo contextualizado. La relevancia del contexto en el análisis y diseño institucionales, Porrúa-Universidad Nacional Autónoma de México, 2006, pp. 1-30.

Przeworski, Adam, "Institutions Matter?", Government and Opposition, vol. 39, núm. 2, 2004, pp. 527-540.

Schedler, Andreas, "The Menu of Manipulation", Journal of Democracy, vol. 13, núm. 2, 2002a, pp. 36-50.

- "The Nested Game of Democratization by Elections", International Political Science Review, vol. 23, núm.1, 2002, pp. 103-122.

, The Politics of Uncertainty: Sustaining and Subverting Electoral Authoritarianism, Oxford, University Press, 2013. 
Secretaría de Gobernación, Sistema de Información Legislativa, México, en www.sil.gobernación.gob.mx

Simpser, Alberto, Why Governments and Parties Manipulate Elections. Theory, Practice, and Implications, Cambridge, University Press, 2013.

Taagepera, Rein y Matthew S. Shugart, Seats and Votes: The Effects and Determinants of Electoral Systems, Nueva York, Yale University Press, 1989.

Tuesta, Fernando, "Reforma política en Perú", en Daniel Zovatto y J. Jesús Orozco Henríquez (coords.), Reforma política y electoral en América Latina 1978-2007, México, Universidad Nacional Autónoma de México, 2008. Ulloa, Félix, El dinero y la democracia. Un caso de estudio, Libros en Red, 2004. Vickery, Chad y Erica Shein, "Assessing Electoral Fraud in New Democracies: Refining the Vocabulary", Washington, DC, White Paper Series, Retrieved from International Foundation for Electoral Systems, 2012. Zovatto, Daniel y Steven Griner (eds.), De las normas a las buenas prácticas. El desafio del financiamiento político en América Latina / From Norms to Good Practices. The Challenge of Political Finance in Latin America, San José, Costa Rica, Organization of the American States and IDEA International, 2004.

\section{APÉNDICE \\ Lista de leyes codificadas y calificadas}

\begin{tabular}{|c|l|l|}
\hline \multicolumn{1}{|c|}{ País } & \multicolumn{1}{|c|}{ Ley } & \multicolumn{1}{c|}{ Año } \\
\hline Argentina & Código Electoral Nacional. Decreto No.2135 & $\begin{array}{l}1983 \text { (con modificaciones } \\
\text { posteriores) }\end{array}$ \\
\cline { 2 - 3 } & $\begin{array}{l}\text { Ley de Financiamiento de los Partidos Políticos } \\
\text { Ley 26.215 }\end{array}$ & 2007 \\
\cline { 2 - 3 } & $\begin{array}{l}\text { Ley de Democratización de la Representación } \\
\text { Política, la Transparencia y la Equidad Electoral }\end{array}$ & N/D \\
\cline { 2 - 3 } & $\begin{array}{l}\text { Decreto Ley 1285/58 Organización de la Justicia } \\
\text { Nacional }\end{array}$ & $\begin{array}{l}1958 \text { (con modificaciones } \\
\text { posteriores) }\end{array}$ \\
\cline { 2 - 3 } & $\begin{array}{l}\text { Ley 19.108 Organización de la Justicia Nacional } \\
\text { Electoral }\end{array}$ & $\begin{array}{l}1971 \text { (con modificaciones } \\
\text { posteriores) }\end{array}$ \\
\hline Bolivia & Ley del Régimen Electoral. Ley No. 026 & 2010 \\
\cline { 2 - 3 } & $\begin{array}{l}\text { Ley del Órgano Electoral Plurinacional. Ley } \\
\text { No. 018 }\end{array}$ & 2010 \\
\hline
\end{tabular}




\section{APÉNDICE (continúa)}

\begin{tabular}{|c|c|c|}
\hline País & Ley & Año \\
\hline \multirow[t]{4}{*}{ Chile } & $\begin{array}{l}\text { Ley } 19884 \text { sobre Transparencia, Límite y Control } \\
\text { del Gasto Electoral }\end{array}$ & 2013 \\
\hline & $\begin{array}{l}\text { Ley No. } 18.700 \text { Ley Orgánica Constitucional } \\
\text { sobre Votaciones Populares y Escrutinios }\end{array}$ & 2012 \\
\hline & $\begin{array}{l}\text { Ley No. } 18.556 \text { Ley Orgánica Constitucional } \\
\text { sobre Sistema de Inscripciones Electorales y } \\
\text { Servicio Electoral }\end{array}$ & 2012 \\
\hline & $\begin{array}{l}\text { Ley Orgánica Constitucional del Tribunal } \\
\text { Calificador de Elecciones }\end{array}$ & 2012 \\
\hline \multirow[t]{4}{*}{ Colombia } & Constitución Política & 2005 \\
\hline & Decreto 2241 de 1986 Código Electoral & 1986 \\
\hline & Código Penal & 2000 \\
\hline & $\begin{array}{l}\text { Ley 130, del } 23 \text { de Marzo de } 1994 \text { Estatuto } \\
\text { Básico de los Partidos y Movimientos Políticos }\end{array}$ & 1994 \\
\hline \multirow[t]{3}{*}{ Costa Rica } & Código Electoral Ley No. 8765 & 2009 \\
\hline & Constitución Política & $\begin{array}{l}1949 \text { (con reformas } \\
\text { posteriores) }\end{array}$ \\
\hline & $\begin{array}{l}\text { Ley Orgánica del Tribunal Supremo de } \\
\text { Elecciones y del Registro Civil Ley No. } 3504\end{array}$ & 1965 \\
\hline Ecuador & Ley Orgánica Electoral Código de la Democracia & 2009 \\
\hline \multirow[t]{2}{*}{ El Salvador } & Código Electoral & 2012 \\
\hline & Código Penal & $\mathrm{N} / \mathrm{D}$ \\
\hline Guatemala & $\begin{array}{l}\text { Ley Electoral y de Partidos Políticos Decreto } \\
\text { No. 1-85 }\end{array}$ & 2007 \\
\hline \multirow[t]{3}{*}{ Honduras } & $\begin{array}{l}\text { Ley Electoral y de las Organizaciones Políticas y } \\
\text { sus Reformas }\end{array}$ & 2004 \\
\hline & Constitución Política & 1982 \\
\hline & Decreto No. 307 & $\mathrm{~N} / \mathrm{D}$ \\
\hline México & $\begin{array}{l}\text { Código Federal de Instituciones y } \\
\text { Procedimientos Electorales }\end{array}$ & 2008 \\
\hline Nicaragua & Ley Electoral Ley No. 331 & 2000 \\
\hline \multirow[t]{2}{*}{ Panamá } & Código Electoral & 2007 \\
\hline & Constitución Política & 2004 \\
\hline \multirow[t]{2}{*}{ Paraguay } & Ley No. 834 Código Electoral & 1996 \\
\hline & Constitución Política & 1992 \\
\hline
\end{tabular}


APÉNDICE (concluye)

\begin{tabular}{|l|l|l|}
\hline \multicolumn{1}{|c|}{ País } & \multicolumn{1}{c|}{ Ley } & \multicolumn{1}{c|}{ Año } \\
\hline \multirow{4}{*}{ Perú } & Ley Orgánica de Elecciones No. 26859 & N/D \\
\cline { 2 - 3 } & Ley de Partidos Políticos & 2003 \\
\cline { 2 - 3 } & Código Penal & N/D \\
\cline { 2 - 3 } & Constitución Política & 2005 \\
\hline \multirow{3}{*}{ Uruguay } & Ley de Elecciones & 2000 \\
\cline { 2 - 3 } & Constitución Política & 1967 \\
\hline \multirow{3}{*}{ Venezuela } & Ley Orgánica de Procesos Electorales & N/D \\
\cline { 2 - 3 } & Ley Orgánica del Poder Electoral & 2002 \\
\cline { 2 - 3 } & Constitución Política & 2009 \\
\hline
\end{tabular}

